\title{
Intracellular Amyloid Precursor Protein Sorting and Amyloid- $\beta$ Secretion Are Regulated by Src-Mediated Phosphorylation of Mint2
}

\author{
Jeremy Chaufty, ${ }^{\star}$ Sarah E. Sullivan, ${ }^{\star}$ and Angela Ho \\ Department of Biology, Boston University, Boston, Massachusetts 02215
}

\begin{abstract}
Mint adaptor proteins bind to the membrane-bound amyloid precursor protein (APP) and affect the production of pathogenic amyloid- $\beta$ $(\mathrm{A} \beta)$ peptides related to Alzheimer's disease (AD). Previous studies have shown that loss of each of the three Mint proteins delays the age-dependent production of amyloid plaques in transgenic mouse models of AD. However, the cellular and molecular mechanisms underlying Mints effect on amyloid production are unclear. Because $\mathrm{A} \beta$ generation involves the internalization of membrane-bound APP via endosomes and Mints bind directly to the endocytic motif of APP, we proposed that Mints are involved in APP intracellular trafficking, which in turn, affects A $\beta$ generation. Here, we show that APP endocytosis was attenuated in Mint knock-out neurons, revealing a role for Mints in APP trafficking. We also show that the endocytic APP sorting processes are regulated by Src-mediated phosphorylation of Mint2 and that internalized APP is differentially sorted between autophagic and recycling trafficking pathways. A Mint2 phosphomimetic mutant favored endocytosis of APP along the autophagic sorting pathway leading to increased intracellular A $\beta$ accumulation. Conversely, the Mint2 phospho-resistant mutant increased APP localization to the recycling pathway and back to the cell surface thereby enhancing A $\beta 42$ secretion. These results demonstrate that Src-mediated phosphorylation of Mint 2 regulates the APP endocytic sorting pathway, providing a mechanism for regulating $\mathrm{A} \beta$ secretion.
\end{abstract}

\section{Introduction}

A pathological hallmark of Alzheimer's disease $(\mathrm{AD})$ is the deposition of amyloid plaques that consist of amyloid- $\beta$ (A $\beta)$ peptides. $A \beta$ is produced by the sequential proteolytic cleavage of the amyloid precursor protein (APP) specifically by $\beta$ - and $\gamma$-secretases (for review, see Hardy and Selkoe, 2002; Small and Gandy, 2006). The amyloidogenic cleavage of APP begins with $\beta$-secretase, which generates the soluble APP ectodomain and a C-terminal fragment (CTF $\beta)$. CTF $\beta$ is then cleaved by $\gamma$-secretase (a multimeric complex that consists of APH-1, nicastrin, presenilin and PEN2) to release $\mathrm{A} \beta 40$ and $\mathrm{A} \beta 42$, the latter having an increased propensity to form amyloid aggregates found in the brains of AD patients. Alternatively, $\alpha$-secretase cleaves APP within the $\mathrm{A} \beta$ region to initiate the non-amyloidogenic pathway.

Intracellular transport and subcellular colocalization of APP with the different secretases are crucial determinants of APP pro-

\footnotetext{
Received Feb. 8, 2012; revised May 1, 2012; accepted May 20, 2012.

Author contributions: J.C., S.E.S., and A.H. designed research; J.C. and S.E.S. performed research; J.C., S.E.S., and A.H. analyzed data; J.C. and A.H. wrote the paper.

This work was supported by grants from the National Institutes of Health (K01 AG027311 to A.H.) and the Alzheimer's Association (IIRG-09-130591 to A.H.) We thank Drs. T.C. Südhof, H. Man, and U. Beffert for plasmids and antibodies, and thank Dr. T. D. Gilmore and members of the laboratory for comments and suggestions. We are grateful to M. Piacentino and Drs. M. Matos, T. Blute, H. Man, and L. Jarzylo for their help and excellent technical assistance.

*J.C. and S.E.S. contributed equally to this work.

The authors declare no competing financial interests.

Correspondence should be addressed to Angela Ho, Department of Biology, Boston University, 5 Cummington Street, Boston, MA 02215. E-mail: aho1@bu.edu.

DOI:10.1523/JNEUROSCI.0602-12.2012

Copyright $\odot 2012$ the authors $\quad 0270-6474 / 12 / 329613-13 \$ 15.00 / 0$
}

cessing and $\mathrm{A} \beta$ production (Small and Gandy, 2006; Thinakaran and Koo, 2008). Deletion of the APP cytoplasmic endocytic motif or inhibition of endocytosis has been shown to reduce $A \beta$ levels, thus indicating that $\mathrm{A} \beta$ generation involves the internalization of membrane-bound APP via endosomes (Koo and Squazzo, 1994; Ring et al., 2007; Cirrito et al., 2008). The sorting signal that regulates endocytic processing of APP required for $A \beta$ generation lies in the highly conserved YENPTY sequence (Haass et al., 1994). This YENPTY motif of APP interacts with phosphotyrosine-binding (PTB) domains of adaptor proteins, such as Mint proteins (Borg et al., 1996). Each of the three Mint family members consists of an isoform-specific N-terminus and a conserved C-terminus that contains a PTB domain which binds APP, and two PDZ domains that bind a number of proteins, including presenilins (Okamoto and Südhof, 1997, 1998; Lau et al., 2000; Biederer et al., 2002). We have previously shown that the APPMint interaction is biologically relevant as loss of individual Mint proteins delays the age-dependent production of amyloid plaques in transgenic mouse models of AD (Ho et al., 2008). However, the cellular and molecular mechanisms underlying Mints effect on APP processing remain unclear.

Increased tyrosine phosphorylation mediated by Src family of tyrosine kinases plays a central role in $\mathrm{AD}$ (Williamson et al., 2002; Gianni et al., 2003; Lee, 2005). In particular, Src-mediated tyrosine phosphorylation is responsible for regulating the sorting of many cell-surface proteins along the clathrin-mediated endocytic pathway (Wilde et al., 1999; Kametaka et al., 2005; Delom and Fessart, 2011). Also, the phosphorylation state of APP and/or its interacting proteins plays an important role in APP sorting 
and $\mathrm{A} \beta$ production (Bonifacino and Traub, 2003). Herein, we demonstrate that APP endocytosis is decreased in neurons lacking Mint proteins, suggesting that Mints are important regulators of APP endocytosis. We show that Mints are differentially phosphorylated by the Src family of kinases and that Src-mediated phosphorylation of Mint2 regulates the sorting of intracellular APP, which in turn modulates the production of secreted $A \beta$. These findings reveal a role for phosphorylation of Mint 2 in regulating APP sorting and secreted $\mathrm{A} \beta$ production that are relevant to $\mathrm{AD}$ pathogenesis.

\section{Materials and Methods}

Plasmids. Constitutively active pUSEamp-Src Y527F plasmid was obtained from Millipore. pCMV5-Fyn, pCMV5-Lyn, pCMV5-Yes, pCMV5-Shc, pCMV5-Dab1 and pCMV-c-Src were provided by Dr. Uwe Beffert (Boston University). pCMV5 rat Mint1, pCMV5 rat Mint2, pCMV5 rat Mint3, pCMV5 human APP695 and pCMV5 human APP containing the Swedish mutation plasmids were kindly provided by Dr. Thomas Südhof (Stanford University, Stanford, CA). All Mint2 plasmids were derived from rat Mint2 cDNA. Mint2 phospho-mutants were generated using the QuikChange XL kit (Stratagene) to mutate tyrosine residues 86,110 and 193 to glutamic acid (Y3E) or phenylalanine (Y3F). Resulting cDNAs were inserted into pEGFP-C3 (Invitrogen) to synthesize EGFP-Mint2 wild-type (EGFP-Mint2-WT), EGFP-Mint2-Y3E or EGFP-Mint2-Y3F plasmids. For lentivirus production, Mint2-WT, Mint2-Y3E or Mint2-Y3F was inserted into the pLitmusIRES shuttle vector with a $5^{\prime}$ IRES (internal ribosome entry site) and subsequently inserted into pFUW-NLS-EGFP-cre to generate pFUW-EGFP-cre-IRESMint2-WT, -Mint2-Y3E and -Mint2-Y3F plasmids. To generate GSTMint2 peptides for in vitro phosphorylation analysis, PCR was used to amplify the rat Mint2 N-terminal region (Mint2-N; residues 1-399), the Mint2 N-terminal region containing Y3F mutations (Mint2-N-Y3F; residues 1-399), the Mint2-PTB domain (residues 363-546; Matos et al., 2012), or the Mint2 C-terminal region (Mint2-C; residues 546-750) which were then inserted into pGEX-KG. APP $\Delta$ CT15 (residues 1-680) was amplified by PCR using human APP695 as a template and inserted into the pCMV5 mammalian expression vector. Lentiviral c-Src used for overexpression in primary neurons was generated by inserting fulllength murine $\mathrm{c}$-Src into the pFUW lentiviral vector.

Transient transfection of cell lines and immunocytochemistry. Cells were grown to 50\% confluency in DMEM and were transfected using FuGENE6 reagent (Promega). Cells were washed with PBS and lysed directly in SDS sample buffer for immunoblot analysis or processed for immunolocalization $48 \mathrm{~h}$ post-transfection. COS7 cells plated on Matrigel (BD Biosciences)-coated coverslips were fixed in cold absolutemethanol for $10 \mathrm{~min}$ at $-20^{\circ} \mathrm{C}$, permeabilized in $0.1 \%$ saponin/PBS, and blocked in $0.01 \%$ saponin $/ 5 \%$ milk in PBS (PBSS). Primary antibody incubation was performed in PBSS overnight at $4^{\circ} \mathrm{C}$. Following PBS washes, cells were incubated for $1 \mathrm{~h}$ with goat anti-rabbit or goat antimouse secondary antibodies conjugated to Alexa Fluor 546 or Alexa Fluor 633 IgG (Invitrogen). Labeled cells were washed in PBS, mounted in ProLong Gold with DAPI (Invitrogen) and imaged with a Zeiss-MZ6 fluorescence microscope.

In vitro phosphorylation assay. Plasmids for the expression of GSTfusion proteins were transformed into BL21 DE3 bacteria and expression was induced using $200 \mu \mathrm{M}$ IPTG. Two hours following induction, cells were lysed and proteins were purified using glutathione Sepharose beads (GE Healthcare). GST-Mint2 peptide ( $5 \mu \mathrm{g}$ ) was incubated with $250 \mu \mathrm{M}$ ATP (Cell Signaling Technology) containing $0.16 \mu \mathrm{Ci} / \mu \mathrm{l}{ }^{32} \mathrm{P}-\gamma \mathrm{ATP}$ (PerkinElmer) and $100 \mathrm{ng}$ of purified c-Src (Cell Signaling Technology) for $5 \mathrm{~min}$ in tyrosine kinase buffer (600 mM HEPES, pH 8.0, $50 \mathrm{~mm}$ $\left.\mathrm{MgCl}_{2}, 50 \mathrm{mM} \mathrm{MnCl}_{2}, 30 \mu \mathrm{M} \mathrm{Na} \mathrm{VO}_{4}\right)$. Immobilized GST-fusion proteins were washed three times with tyrosine kinase buffer supplemented with $0.5 \%$ Triton X-100. GST-peptides were eluted from beads by boiling for $5 \mathrm{~min}$ and subjected to SDS-PAGE. Total protein quantities were estimated using Coomassie Brilliant Blue staining. Incorporation of ${ }^{32} \mathrm{P}$ was measured by transferring proteins to a nitrocellulose membrane and the relative radioactivity was captured on film (Kodak) using an autoradiograph intensifying screen.

Cortical cultures and lentiviral infection. We used an established AD mouse model that is homozygous for the floxed mutant alleles of all three Mint genes carrying the double transgene of mutant APPswe/PS1 $E$ E9 $\left(\mathrm{MTF}^{\mathrm{tg}}\right)$ that overproduce human A $\beta$ levels (Ho et al., 2008). Highdensity MTF $^{\text {tg }}$ cortical cultures were prepared from newborn mice of either sex and cells were dissociated with trypsin for $5 \mathrm{~min}$ at $37^{\circ} \mathrm{C}$, triturated and plated onto 24-well plates coated with Matrigel (Ho et al., 2006,2008 ). Neurons were maintained in culture at $37^{\circ} \mathrm{C}$ in a humidified incubator with $95 \%$ air and $5 \% \mathrm{CO}_{2}$. Recombinant lentiviruses were produced by transfecting HEK293T cells with plasmids for viral enzymes and envelope proteins (pRSV/REV, pMDLg/RRE and pVSVG kindly provided by Dr. Thomas Südhof) using FuGENE6 reagent (Roche) as previously described (Ho et al., 2006, 2008). For expression of Mint 2 and Mint2 phospho-mutants in Mint triple knock-out neurons, we used the bicistronic pFUW-GFP-cre-IRES-Mint2-WT, Mint2-Y3E and Mint2Y3F plasmids for transfection into HEK293T cells. Conditioned medium containing lentivirus was harvested after $48 \mathrm{~h}$, centrifuged at $1000 \times \mathrm{g}$ for $10 \mathrm{~min}$, and immediately used for neuronal infection at $5 \mathrm{~d}$ in vitro (DIV). Neurons were sustained in this medium until $2 \mathrm{~d}$ before biochemical analysis (12-14 DIV) when $25 \%$ of the culture volume was exchanged for fresh growth medium.

Biotinylation assay for APP endocytosis and surface expression. Highdensity MTF $^{\text {tg }}$ cortical cultures were incubated with $1 \mathrm{mg} / \mathrm{ml}$ sulfoNHS-SS-biotin (Fisher Scientific) in PBS for 20 min on ice. Unbound biotin was quenched with $50 \mathrm{~mm}$ glycine, $0.5 \% \mathrm{BSA}$ in PBS and neurons were incubated in their original growth media for 5 and $30 \mathrm{~min}$ at $37^{\circ} \mathrm{C}$ to permit internalization of biotin-labeled proteins. Remaining surface biotin was cleaved with glutathione cleavage buffer ( $50 \mathrm{~mm}$ glutathione in $75 \mathrm{~mm} \mathrm{NaCl}, 10 \mathrm{~mm}$ EDTA, $1 \% \mathrm{BSA}$, and $0.075 \mathrm{~N} \mathrm{NaOH}$ ) for $15 \mathrm{~min}$ at $4^{\circ} \mathrm{C}$ and neutralized with $10 \mathrm{~mm}$ iodoacetamide and PBS washes leaving only endocytosed proteins biotinylated. Cells were then lysed with RIPA buffer (65 mM Tris, pH 7.4, $150 \mathrm{~mm} \mathrm{NaCl,} \%$ Triton, 0.1\% SDS, $0.5 \%$ Na-deoxycholate, 1 mм EDTA, pH 8.0, $50 \mathrm{~mm} \mathrm{NaH}_{2} \mathrm{PO}_{4}, 50 \mathrm{~mm} \mathrm{NaF}, 10$ $\mathrm{mM} \mathrm{Na}_{4} \mathrm{P}_{2} \mathrm{O}_{7}, 1 \mathrm{~mm} \mathrm{Na}_{3} \mathrm{VO}_{4}$, and Protease Inhibitor Cocktail) for $1 \mathrm{~h}$ with rotating at $4^{\circ} \mathrm{C}$. Lysates were clarified by centrifugation at $14,000 \times$ $g$ for $20 \mathrm{~min}$ at $4^{\circ} \mathrm{C}$. Supernatants containing $100 \mu \mathrm{g}$ of protein were incubated with RIPA-equilibrated Neutravidin beads (50:50 slurry; Fisher Scientific) overnight at $4^{\circ} \mathrm{C}$ with gentle rocking to precipitate the biotinylated proteins. Beads were washed several times with RIPA buffer and spun at $800 \times g$ for $1 \mathrm{~min}$. Proteins were eluted from the Neutravidin beads by boiling for $10 \mathrm{~min}$ in reducing sample buffer, resolved by SDS-PAGE and immunoblotted for APP. The percentage internalized APP was calculated by measuring the band intensity of the internalized APP $\left(\mathrm{APP}_{\mathrm{I}}\right)$ compared with total APP $\left(\mathrm{APP}_{\mathrm{T}}\right)$ levels. For APP surface expression, cortical cultures were incubated with 1 $\mathrm{mg} / \mathrm{ml}$ sulfo-NHS-LC-Biotin (Fisher Scientific) in PBS for $20 \mathrm{~min}$ on ice, quenched with Tris-buffered saline $(150 \mathrm{~mm} \mathrm{NaCl}$ and $50 \mathrm{~mm}$ Tris, pH 7.5), and lysed with RIPA buffer. Biotinylated surface proteins were precipitated and surface expression was determined by comparing surface APP $\left(\mathrm{APP}_{\mathrm{S}}\right)$ to $\mathrm{APP}_{\mathrm{T}}$.

Recycling experiments. Live hippocampal $\mathrm{MTF}^{\mathrm{tg}}$ neurons were incubated with an antibody against an N-terminal epitope of APP (clone 22C11; Millipore) for $15 \mathrm{~min}$ and a cold (nonconjugated) secondary antibody for another 15 min to block preexisting cell surface APPs as previously described (Lu et al., 2001). Neurons were then incubated for $30 \mathrm{~min}$ at $37^{\circ} \mathrm{C}$ and fixed with $4 \%$ paraformaldehyde for $10 \mathrm{~min}$ at room temperature and stained with the same anti-APP primary antibody overnight at $4^{\circ} \mathrm{C}$ followed by goat anti-mouse secondary antibodies conjugated to Alexa Fluor 546 (Invitrogen) for $1 \mathrm{~h}$ at room temperature. Images were captured using a FluoView FV10i scanning confocal microscope and quantitative immunofluorescence was performed using ImageJ software (NIH). Microscope settings (laser gain and threshold filters) remained constant for all conditions. APP recycling was also measured by the loss of internalized APP that was specifically labeled with cleavable disulfide-linked biotin. High-density MTF ${ }^{\text {tg }}$ cortical cultures were surface biotinylated as above, and cells were transferred to $37^{\circ} \mathrm{C}$ for 5 min to allow endocytosis to occur. Cells were then cooled to $4^{\circ} \mathrm{C}$ to stop 
membrane trafficking and remaining surface biotin was cleaved with glutathione. Cells were returned to conditioned medium at $37^{\circ} \mathrm{C}$ for 30 min to allow internalized APP to recycle before the cells were cooled to $4^{\circ} \mathrm{C}$ and cleaved with glutathione. Internalized biotinylated APP was isolated by streptavidin precipitation and APP was detected by immunoblot analysis as described above.

APP internalization and immunocytochemistry in primary neurons. For localization of internalized APP, live hippocampal MTF ${ }^{\text {tg }}$ neurons were incubated with an antibody against an N-terminal epitope of APP (clone 22C11; Millipore) for $15 \mathrm{~min}$ at room temperature. Neurons were then washed in ice-cold artificial CSF (ACSF; $150 \mathrm{~mm} \mathrm{NaCl}, 10 \mathrm{~mm}$ HEPES, 30 $\mathrm{mm} \mathrm{KCl}, 2.6 \mathrm{~mm} \mathrm{CaCl}_{2}, 1 \mathrm{~mm} \mathrm{MgCl}_{2}, 10 \mathrm{~mm}$ D-glucose, $\mathrm{pH}$ 7.4) to remove unbound antibody and then incubated at $37^{\circ} \mathrm{C}$ for various times to promote internalization. The remaining surface-bound antibodies were liberated in acid stripping buffer $(0.5 \mathrm{M} \mathrm{NaCl}, 0.2 \mathrm{M}$ acetic acid $)$ for 5 min on ice, followed by cold ACSF washes and fixation with $4 \%$ paraformaldehyde for $10 \mathrm{~min}$ at room temperature. Neurons were permeabilized in $0.3 \%$ Triton X-100 in ACSF for 10 min and incubated with goat anti-mouse secondary antibodies conjugated to Alexa Fluor 546 (Invitrogen) for $1 \mathrm{~h}$ at room temperature. For colocalization of internalized APP with intracellular marker proteins, neurons were incubated with primary antibodies against markers for Golgi, endosomes, lysosomes and autophagosomes overnight at $4^{\circ} \mathrm{C}$ followed by appropriate species-specific Alexa Fluor 633 secondary antibodies (Invitrogen). Images were captured using a FluoView FV10i scanning confocal microscope and quantitative image analysis for subcellular colocalization was performed using ImageJ software (NIH) and JACoP (Just Another Co-localization Plugin; Bolte and Cordelières, 2006) using Manders' coefficient (Manders et al., 1992) to reflect colocalization of the $546 \mathrm{~nm}$ channel (APP) to the $633 \mathrm{~nm}$ channel (LC3). Microscope settings (laser gain and threshold filters) remained constant for all conditions.

A $\beta$ peptide measurement. Conditioned medium was collected from $\mathrm{MTF}^{\mathrm{tg}}$ neuronal cultures, and centrifuged at $15,000 \times \mathrm{g}$ for $5 \mathrm{~min}$ at $4^{\circ} \mathrm{C}$. The supernatant was subjected to ELISA measurement for human A $\beta 42$ according to the manufacturer's instructions (27711, ImmunoBiological Laboratories kits).

Antibodies. APP 22C11 (MAB348, Millipore), APP U955, Mint1 P730 (generous gifts from Dr. Thomas Südhof), Mint2 (M3319, Sigma), Mint3 (PA1-072, Thermo Scientific), tubulin DM1A (T6199, Sigma), c-Src (05-184, Millipore), Rab5 (610282, BD Biosciences), GM130 (610822, BD Biosciences), LAMP1 (sc5570, Santa Cruz Biotechnology), and LC3 (4108S, Cell Signaling Technology).

Statistical analysis. We used a paired Student's $t$ test or ANOVA.

\section{Results}

\section{Mints mediate APP internalization in primary neurons}

Given that Mints bind to the conserved endocytic motif of APP (Borg et al., 1996), we hypothesized that Mints serve as regulators of APP endocytosis. To determine whether Mints affect APP endocytosis, we examined APP internalization in Mint knock-out neurons using a cell-surface biotinylation assay. We used an established $\mathrm{AD}$ mouse model that is carrying the double transgene of mutant APPswe/PS1 $\triangle E 9$ ( MTF $^{\text {tg }}$ ) that overproduces human $\mathrm{A} \beta$ (Ho et al., 2008). We cultured neurons from newborn MTF ${ }^{\mathrm{tg}}$ mice and infected them with lentivirus that either expresses a functional cre recombinase or an inactive mutant cre recombinase as a control. We have previously shown that neuronal cultures infected with control virus showed normal expression of all three Mints, whereas neurons infected with the cre recombinase virus showed complete deletion of all Mints (Fig. 1A) (Ho et al., 2006, 2008). When $\mathrm{MTF}^{\text {tg }}$ cortical neurons were biotinylated to label all surface proteins at $4^{\circ} \mathrm{C}$ and returned to $37^{\circ} \mathrm{C}$ for $30 \mathrm{~min}$ of internalization, we found a substantial amount of APP internalization in control neurons expressing Mints, while Mint knockout neurons demonstrated a 57\% decrease in APP internalization (Fig. $1 B$ ). To exclude the possibility that reduced APP internal-
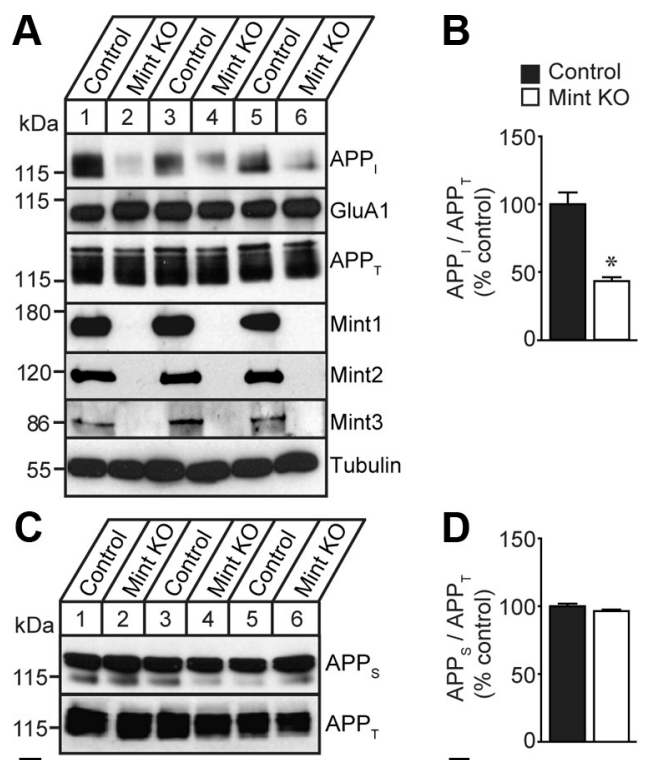

E
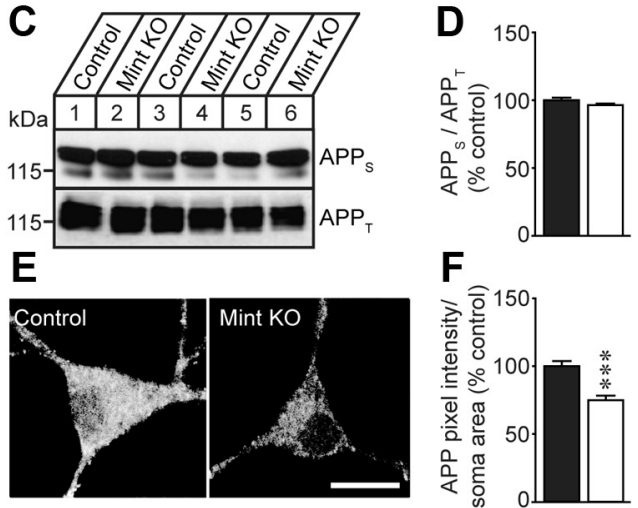

$\mathbf{F}$
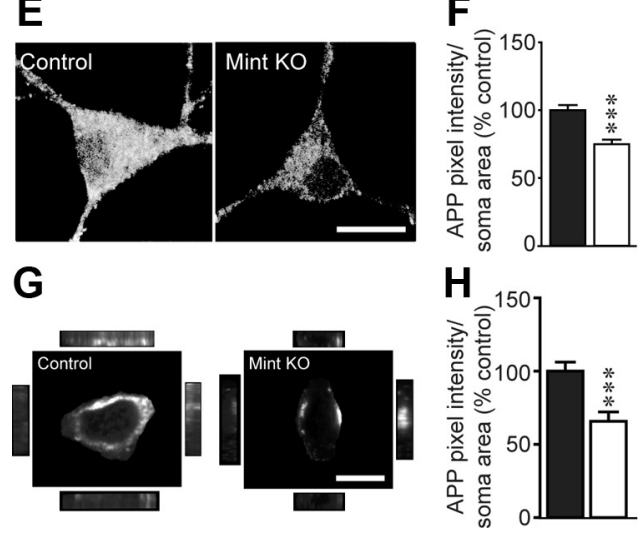

Figure 1. APP internalization is reduced in conditional Mint knock-out (KO) neurons. MTF $^{\text {tg }}$ neurons were infected with either lentiviral inactive (Control) or active crerecombinase to delete all Mint proteins (Mint K0), respectively. $\boldsymbol{A}, \boldsymbol{B}$, Representative immunoblots and quantification for surface biotinylated proteins that were internalized for $30 \mathrm{~min}$ at $37^{\circ} \mathrm{C}$ and precipitated with Neutravidin agarose beads. Precipitated proteins were blotted for internalized $A P P\left(A P P_{1}\right)$ and GluA1. Input lysates were probed for $A_{P P}$ and Tubulin. Efficient knock-out of Mint proteins were represented in lanes 2, 4, and 6 reflecting Mint1, 2 and 3 protein levels. The amount of internalized APP was taken as the band intensity of $A P P_{1}$ relative to $A P P_{T}$ present in the lysates and expressed as percentage control. C, D, Representative immunoblots and quantification for control and Mint KO neurons that have been surface biotinylated. Precipitated proteins and total input lysates were immunoblotted for APP and the amount of surface APP (APP $)$ was taken as the measure of band intensity relative to $\mathrm{APP}_{\mathrm{T}}$ and expressed as percentage control. $\boldsymbol{E}$, Live cell endocytosis assay of MTF ${ }^{\text {tg }}$ neurons incubated with an extracellular N-terminal APP antibody (22C11) and internalized for 30 min before stripping of excess surface antibody and fixation. $\boldsymbol{F}$, Internalized APP immunostaining was visualized by confocal microscopy and quantification of APP internalized was taken as a measure of pixel intensity within a defined soma area and expressed as percentage control $(n=3 / 22$ represents number of independent experiments and total number of neurons assessed). $\mathbf{G}$, Live cell recycling assay of MTF ${ }^{\text {tg }}$ neurons. After blocking existing cell surface APPs with primary antibody recognizing the $\mathrm{N}$-terminal extracellular domain of APP and cold (non-fluorescenceconjugated) secondary antibody, neurons were incubated at $37^{\circ} \mathrm{C}$ for $30 \mathrm{~min}$. The newly inserted cell surface APPs were visualized using confocal microscopy. Representative images signify newly inserted cell surface APP from orthogonal projections of confocal $\boldsymbol{z}$-stacks. $\boldsymbol{H}$, Newly inserted cell surface APP was visualized by confocal microscopy and quantification of APP reinsertion was taken as a measure of pixel intensity within a defined soma area and expressed as percentage control ( $n=2 / 17$ represents number of independent experiments and total number of neurons). ${ }^{*} p<0.05,{ }^{* * *} p<0.005$. To avoid bias, the investigator was blind to whether cultured neurons were infected with functional or inactive cre recombinase. Scale bar, $20 \mu \mathrm{m}$. 
ization is due to a general defect in receptor-mediated endocytosis, we examined the internalization of excitatory glutamate receptor GluA1, a protein that is internalized independent of Mints. We found no change in GluA1 internalization in control and Mint knock-out neurons, indicating that Mints specifically affect the endocytosis of cell-surface APP (Fig. 1A). Also, there was no change in the total amount of APP protein expression in Mint knock-out neurons (Fig. 1A). It is possible that the reduced APP internalization in Mint knock-out neurons is a result of impaired transit of APP to the cell surface. Therefore, we measured cell surface APP and found no significant difference in surface APP expression in control and Mint knock-out neurons, indicating that the steady-state surface expression of APP is not affected in Mint knock-out neurons (Fig. 1C,D).

We next performed a live cell endocytosis assay to quantify the relative amount of intracellular APP in cultured hippocampal MTF $^{\text {tg }}$ neurons that contain or lack Mints. Neurons were incubated with an extracellular N-terminal APP antibody and subsequently incubated at $37^{\circ} \mathrm{C}$ for $30 \mathrm{~min}$ to allow internalization of antibody-coupled APP. Remaining surface-bound antibodies were acid-stripped and internalized APP was visualized following cell permeabilization using a fluorescent-conjugated secondary antibody. Internalized APP was markedly different in control and Mint knock-out neurons (Fig. 1E). Mint knock-out neurons showed a significant $25 \%$ reduction in internalized APP compared with control neurons, suggesting that Mints modulate APP trafficking by regulating APP internalization supporting our biochemical endocytosis analysis (Fig. $1 F$ ). No visible staining was observed in nonpermeabilized cells or cells treated with the endocytic inhibitor Dynasore (data not shown).

The finding that Mint knock-out neurons showed reduced internalized APP without significantly affecting steady-state surface expression suggests that membrane insertion of APP could be regulated by Mint proteins. Such newly inserted APP could arise from intracellular pools through rapid translocation or by recycling of recently internalized APP. To test whether internalized APPs were reinserted back into the plasma membrane and to measure the effect of Mints on APP reinsertion, a recycling assay was performed on control and Mint knock-out neurons (Fig. $1 G, H)$. Preexisting cell surface APPs were blocked by incubation with an extracellular N-terminal APP antibody and then a cold non-fluorescence-conjugated secondary antibody at $4^{\circ} \mathrm{C}$. Neurons were subsequently incubated at $37^{\circ} \mathrm{C}$ for $30 \mathrm{~min}$ to allow for APP insertion. The newly inserted APPs were then labeled with the same primary antibody followed by a fluorescent-conjugated-secondary antibody under nonpermeating conditions. We found newly inserted APP staining on the surface of somas that represent a rapid, constitutive insertion of APP into the plasma membrane in control neurons. However, the number of newly inserted APP staining showed a significant 34\% reduction in Mint knock-out neurons compared with control. These data suggest that a significant fraction of APP is reinserted into the plasma membrane following endocytosis and that the extent of APP reinsertion is decreased by the loss of Mint proteins.

\section{The Src family of tyrosine kinases differentially phosphorylates Mints}

Because tyrosine phosphorylation is important in controlling and regulating neuronal adaptor protein function (Howell et al., 1997), we wanted to determine whether phosphorylation of Mints modulates APP trafficking. We first examined whether Mints are substrates for Src tyrosine kinase because they have been shown to play a central role in AD (Williamson et al., 2002;
Gianni et al., 2003; for review, see Lee, 2005). We transfected HEK293T cells with Mints 1-3 alone or together with constitutively active (Y529F) or inactive (K295M) c-Src kinase and assayed for Mint phosphorylation by immunoblotting with an anti-phosphotyrosine antibody 4G10 (Fig. 2A). Coexpression of constitutively active c-Src kinase resulted in prominent tyrosine phosphorylation of Mints 1 and 2, but not Mint3. Mints 1 and 2 were phosphorylated by Src to a similar extent as the adaptor protein Disabled (Dab1), a known substrate for Src (Howell et al., 1997). In contrast, an inactive c-Src kinase was incapable of stimulating tyrosine phosphorylation of Dab1, Mints 1 and 2. Moreover, in the absence of constitutively active c-Src kinase, Mints 1-3 were not tyrosine phosphorylated in HEK293T cells (data not shown). The differential effects of Src kinase on Mint phosphorylation were not caused by variations in the levels of Mint expression, as indicated by immunoblotting with isoform-specific Mint antibodies (data not shown).

We next examined whether the other Src family kinases, Fyn, Yes or Lyn, could also phosphorylate Mint proteins (Fig. 2 B). We found that Fyn, Yes and Lyn are efficient at phosphorylating Mint1, but not Mints 2 and 3, suggesting that Mints are differentially regulated by the Src family of kinases. In a complementary experiment, HEK293T cells were cotransfected with active or inactive $\mathrm{c}$-Src kinase together with Mint1 or Mint 2 and tyrosine phosphorylated proteins were immunoprecipitated with the 4G10 antibody. Mint1 immunoblotting of anti-phosphotyrosine immunoprecipitates showed that Mint1 was significantly phosphorylated in the presence of constitutively active c-Src kinase, but not in the presence of inactive $\mathrm{c}$-Src or in the absence of exogenously expressed kinase (Fig. 2C). Similarly, Mint2 was phosphorylated by c-Src tyrosine kinase. This confirmed that both neuron-specific Mints 1 and 2 are phosphorylated by Src kinase using an overexpression paradigm. We next performed immunoprecipitation with an anti-phosphotyrosine antibody (4G10) from primary neurons and probed for Mint1 and Mint2 using Western blot to investigate whether Mint1 and Mint2 are tyrosine phosphorylated in neurons. We found that both Mint1 and Mint 2 are endogenously tyrosine phosphorylated in brain detected from Mint1 and Mint2 immunoblotting of antiphosphotyrosine immunoprecipitates (Fig. 2D). We also examined whether APP was a substrate for Src tyrosine kinase and found that neither wild-type APP nor mutant APPswe (APP carrying the Swedish mutation) is phosphorylated by Src, Fyn, Yes or Lyn in this overexpression system (Fig. 2 E).

Because loss of Mint 2 has the largest effect on decreasing A $\beta$ production (Ho et al., 2008), we focused our efforts on characterizing the role of Mint2 phosphorylation on APP trafficking. We first analyzed Mint2 for putative Src kinase sites using NetPhos2.0 and Scansite 2.0 (Blom et al., 1999; Obenauer et al., 2003) and identified three tyrosine sites within the rat Mint2 N-terminal domain (Tyr86, Tyr110 and Tyr193) which are also conserved in the human Mint2 sequence (Fig. 2 F). To determine whether these sites are phosphorylated by Src kinase and to search for additional Src phosphorylation sites, we performed an in vitro phosphorylation assay using GST fusion proteins that spanned the rat Mint2 full-length protein in overlapping fragments: N-terminal region (residues 1-399), conserved Cterminal region consisting of the PTB domain (residues 363546), and the two tandem PDZ domains (residues 546-750; Fig. 2 F). To validate Tyr86, Tyr110 and Tyr193 as sites of phosphorylation, we mutated all three tyrosine residues to phenylalanine (Mint2-Y3F) within the $\mathrm{N}$-terminal fusion protein (residues 1-399). Immobilized fusion proteins were incubated with ${ }^{32} \mathrm{P}-\gamma$ - 

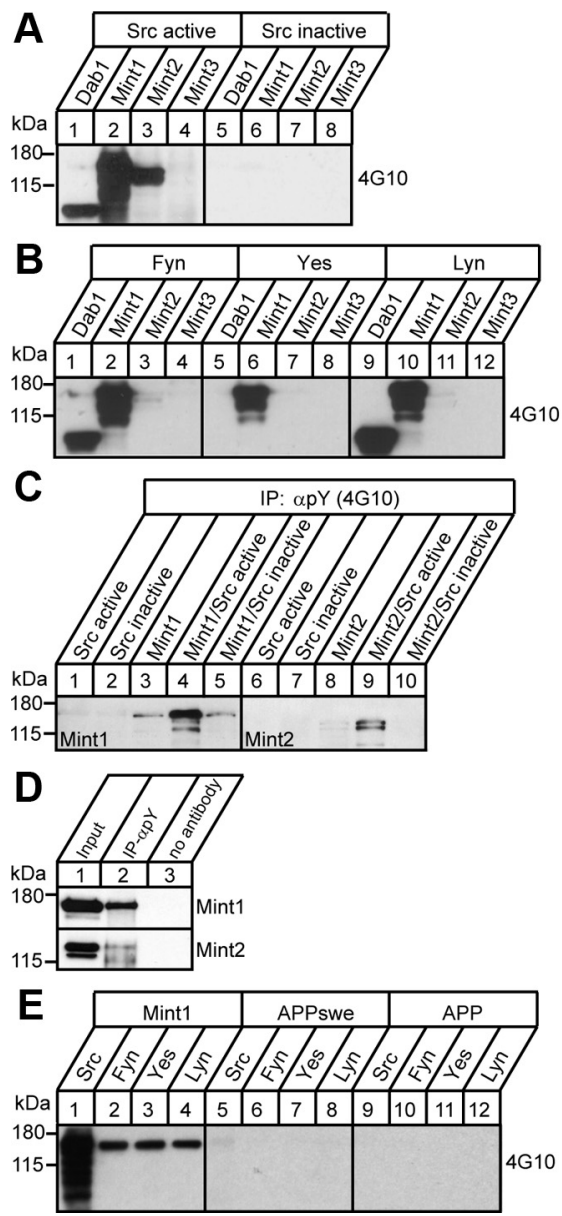

Figure 2. Mints are differentially phosphorylated by Src family of kinases in vitro. HEK293T cells were cotransfected with plasmids expressing Src family kinases and putative substrates. $\boldsymbol{A}, \boldsymbol{B}$, Representative immunoblots of cell lysates expressing constitutively active c-Src, kinase-deficient c-Src (Src inactive), Fyn, Yes, or Lyn kinases with Disabled protein Dab1, Mint1, Mint2 or Mint3 and blotted with a phosphotyrosine-specific antibody 4G10. C, HEK293T cells were transfected with Mint1 or Mint2 in the presence of active or inactive Src kinase or transfected with only a single plasmid. Phosphotyrosine proteins were immunoprecipitated using phosphotyrosine-specific antibody 4G10. Precipitated proteins were analyzed by immunoblotting with Mint1 (lanes 1-5) or Mint2 (lanes 6-10) antibody. D, Phosphotyrosine proteins were immunoprecipitated using phosphotyrosine-specific antibody $4 \mathrm{G} 10$ from primary neuronal cultures. Precipitated proteins were analyzed by immunoblotting with Mint1 or Mint2 antibody. $\boldsymbol{E}$, Representative immunoblots of cell lysates expressing constitutively active c-Src, Fyn, Yes, or Lyn kinases with Mint1, APPswe and wild-type APP and blotted with 4G10. F, Postulated tyrosine phosphorylation sites for Mint2 by Src kinase at amino acid positions 86, 110 and 193 in rat Mint2 was identified. Below are recombinant GST-Mint2 truncated fusion proteins that encompass the Mint2 protein in overlapping fragments: N-terminal region (GST-Mint2-N; residues 1-399), PTB domain (GSTMint2-PTB; residues 363-546) and two tandem PDZ domains (GST-Mint2-C; residues 546-750). G, In vitro phosphorylation assay combining purified Src with GST-Mint2 fusion proteins described in F. Coomassie Brilliant Blue (CBB) staining indicates equal amount of GST protein. $\boldsymbol{H}$, Representative immunoblots of lysates from HEK293T cells cotransfected with Src kinase and Mint2 wild-type (Mint2-WT, lanes 1 and 4), or Mint2 phospho-mutants where tyrosines 86, 110 and 193 were mutated to glutamic acid (Mint2-Y3E, lanes 2 and 5) or phenylalanine (Mint2-Y3F, lanes 3 and 6). I, Relative phosphotyrosine immunoreactivity are quantified by normalizing mean pixel intensity of the $4 \mathrm{G} 10$ signal to that of Tubulin and expressed as percentage of control. ${ }^{* *} p<0.01$, ${ }^{* * *} p<0.005$.

ATP and Src kinase, and analyzed by SDS-PAGE, Coomassie Blue staining and autoradiography (Fig. 2G). The autoradiograph revealed that N-terminal Mint2 was robustly phosphorylated whereas the Mint2 PTB and the PDZ domains were not. Furthermore, phosphorylation of the Mint2-Y3F N-terminal mutant was decreased, confirming that one or more of these three tyrosine residues are substrates for Src kinase. It is likely that the remaining levels of phosphorylation of the Mint2-Y3F $\mathrm{N}$-terminal mutant are due to the presence of other putative Src kinase sites.

To further examine Src-mediated phosphorylation of Mint2, we produced Mint2 mutants that mimic a constitutively active phosphorylated state by mutating all three tyrosine resides to glutamic acid (Mint2Y3E) or a nonphosphorylatable Mint2 mutant (Mint2-Y3F). When HEK293T cells were cotransfected with c-Src kinase and Mint2 phospho-mutants, we found that both phospho-mutants showed significantly decreased phosphorylation compared with Mint2 wild-type (Mint2WT; Fig. $2 H, I$ ). The potential for tyrosine phosphorylation mediated by Src kinase was also examined for each tyrosine residue mutant and found that mutation of all three tyrosines significantly decreased tyrosine phosphorylation by Src compared with single tyrosine residue mutants (data not shown). Together, these results indicate that Mints are differentially regulated by the Src family of kinases and that Mint2 is preferentially phosphorylated at one or more of three tyrosine residues within its $\mathrm{N}$-terminal domain.

\section{Mint2 phosphorylation regulates APP trafficking}

To determine whether phosphorylation of Mint2 alters APP trafficking and localization, we cotransfected COS7 cells with APP and GFP-Mint2-WT, phosphomimetic GFP-Mint2-Y3E or phospho-resistant GFPMint2-Y3F and immunostained for APP. Coexpressed APP with GFP-Mint2-WT was predominantly concentrated in perinuclear compartments and showed diffuse cytoplasmic staining of both Mint2 and APP throughout the cell (Fig. $3 A, B$ ). However, when cells were cotransfected with APP and the phosphomimetic GFPMint2-Y3E mutant, Mint2 and APP were mostly sequestered to large cytoplasmic compartments, resembling vacuoles, in $\sim 60 \%$ of cells (Fig. $3 A, B$ ). Meanwhile, cells cotransfected with APP and the phospho-resistant GFP-Mint2-Y3F mutant showed a different localization pattern for Mint2 and APP with Mint2 predominantly clustered in one distinct perinuclear area (Fig. 3A,B). COS7 cells transfected with only GFP-Mint2-WT, GFP-Mint2-Y3E or GFP-Mint2-Y3F did not show any alterations in Mint2 subcellular distribution (Fig. $3 C$ ), indicating that the localization changes observed with Mint2 were most likely due to an interaction between Mint2 and APP.

To confirm that a direct interaction between Mint2 and APP is required for the localization changes, we cotransfected COS7 cells with GFP-Mint2-WT, GFP-Mint2-Y3E or GFPMint2-Y3F with an APP mutant lacking the last 15 aa of the C terminus (APP $\triangle \mathrm{CT} 15)$ which encompasses the conserved endocytic YENPTY motif, thus preventing direct binding of Mint2 to APP. In the absence of Mint2 and APP binding, we did not observe any localization changes of Mint2, suggesting that a direct interaction between Mint2 and APP is important 

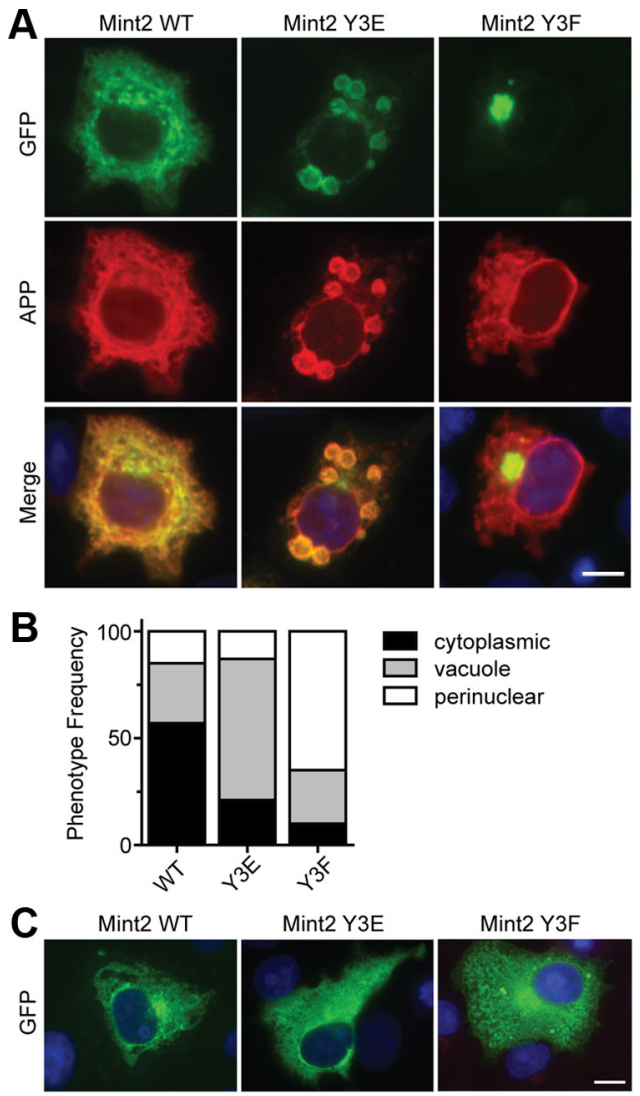

Mint2 Y3F

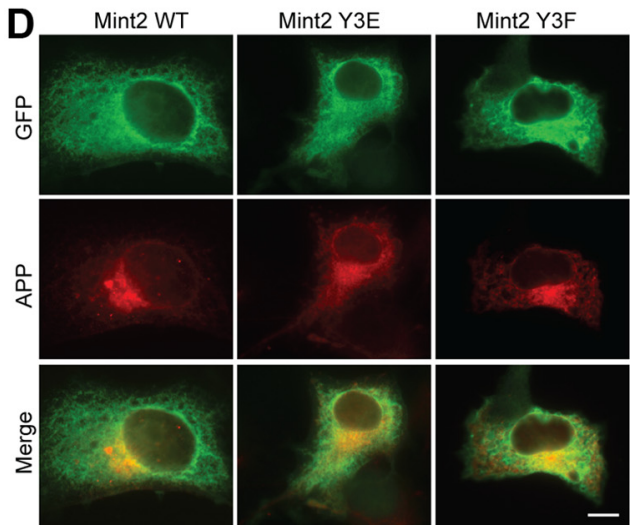

Figure 3. Mint2 phospho-mutants affect APP trafficking. A, COS7 cells were cotransfected with APP and GFP-Mint2-WT, GFP-Mint2-Y3E or GFP-Mint2-Y3F. Representative images of the subcellular localization of GFP-Mint2-WT and phospho-mutants (green), APP immunoreactivity (red) and DAPI nuclear staining (blue) are shown. The top row shows cytoplasmic diffuse localization of both proteins. The middle row represents GFP-Mint2-Y3E colocalized with APP in cytoplasmic vacuoles, whereas the bottom row shows GFP-Mint2-Y3F is sequestered to a distinct perinuclear compartment that differs from that of APP. Phenotypes were assessed in 120 randomly selected cells. $\boldsymbol{B}$, Quantification representing phenotype frequency as described in $\boldsymbol{A}$. C, COS7 cells transfected with only GFP-Mint2-WT, GFP-Mint2-Y3E or GFP-Mint2-Y3F did not show any alterations in Mint2 subcellular distribution suggesting that the localization changes observed in $\boldsymbol{A}$ were due to an interaction between Mint2 and APP. D, COS7 cells were cotransfected with a mutant APP plasmid lacking the last 15 aa in the C-terminal region of APP (APP $\Delta$ C15) and GFP-Mint2-WT, GFP-Mint2-Y3E or GFP-Mint2-Y3F. Scale bars, $20 \mu \mathrm{m}$.

for phosphorylation-dependent changes (Fig. 3D). In fact, the APP mutant predominantly clustered in one distinct perinuclear area (Fig. 3D).

To determine the subcellular fate of APP with Mint2-WT and Mint2 phospho-mutants, we immunolabeled transfected COS7 cells with a panel of subcellular markers for Golgi, endosomes, lysosomes and autophagosomes and assayed for colocalization of these subcellular markers with Mint2. We found that phosphomimetic GFP-Mint2-Y3E predominantly colocalized with the autophagosome marker LC3, thus suggesting that phosphorylated Mint2 complexed with APP is preferentially targeted for the autophagic pathway (Fig. $4 \mathrm{~A}$ ). Interestingly, we found a high degree of colocalization with phospho-resistant GFPMint2-Y3F with the Golgi marker GM130, suggesting that nonphosphorylated Mint2 is predominantly trafficked to the Golgi (Fig. 4B).

To examine whether phosphorylation of Mint2 alters APP binding and stabilization, we cotransfected APP with GFPMint2-WT, GFP-Mint2-Y3E or GFP-Mint2-Y3F mutants in HEK293T cells and performed immunoprecipitation assays. APP selectively coimmunoprecipitated with Mint2 and we did not observe any significant differences in APP binding with Mint 2 phospho-mutants, indicating that phosphorylation of Mint2 did not alter APP binding affinity (Fig. 4C). Moreover, we did not find any changes in APP protein expression when we cotransfected APP with GFP-Mint2-WT, GFP-Mint2-Y3E or GFPMint2-Y3F mutants in HEK293T cells, suggesting that Mint2 phosphorylation does not affect the steady-state distribution of APP expression (Fig. 4D).

\section{Mint2 phosphorylation modulates APP sorting in primary neurons}

To determine whether Mint2 phosphorylation alters APP trafficking in primary neurons, we infected cultured MTF ${ }^{\text {tg }}$ neurons with a bicistronic lentiviral vector with an IRES segment to coexpress cre recombinase (placed in the first cistron) and Mint2 (placed downstream of the IRES). This allowed us to examine the effects of the Mint2 phospho-mutants in a Mint knock-out background and determine the effects of these mutants on cell surface levels of APP by biotinylation assay. Expression of APP was not different between Mint 2 wild-type and phospho-mutants on the plasma membrane or in total cell lysates, supporting our findings that Mint proteins do not affect steady-state surface APP expression (Fig. 5A).

To examine whether phosphorylation of Mint2 affects APP endocytosis, we performed biotinylation assays of APP internalization on cultured MTF ${ }^{\text {tg }}$ cortical neurons infected with creIRES-Mint2-WT, cre-IRES-Mint2-Y3E or cre-IRES-Mint2-Y3F (Fig. 5B). We found that the phosphomimetic Mint2-Y3E mutant significantly accelerated APP internalization by $37 \%$ after 5 min compared with Mint2-WT and phospho-resistant Mint2Y3F mutant (Fig. 5C). We next performed a live cell endocytosis assay to further characterize the effect of Mint2 phosphorylation on APP internalization (Fig. 5D). After 5 min of endocytosis, internalized APP was significantly enhanced by $28 \%$ in MTF $^{\text {tg }}$ neurons expressing the phosphomimetic Mint2-Y3E mutant compared with Mint2-WT and phospho-resistant Mint2-Y3F mutant (Fig. 5E) and showed extensive colocalization with the early endosomal marker Rab5 (Fig. 5D), suggesting that phosphorylation of Mint2 accelerates APP endocytosis.

Although initially localized to early endosomes, internalized APP is subsequently sorted along intracellular pathways. To determine APP transit through endocytic compartments, we immunolabeled with a panel of subcellular markers for Golgi, late endosomes, lysosomes and autophagosomes to examine the localization of endocytosed APP in cultured MTF ${ }^{\text {tg }}$ neurons infected with cre-IRES-Mint2-WT, cre-IRES-Mint2-Y3E or creIRES-Mint2-Y3F. After $5 \mathrm{~min}$ of endocytosis, we found that 
A

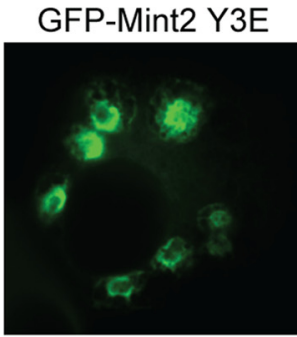

B
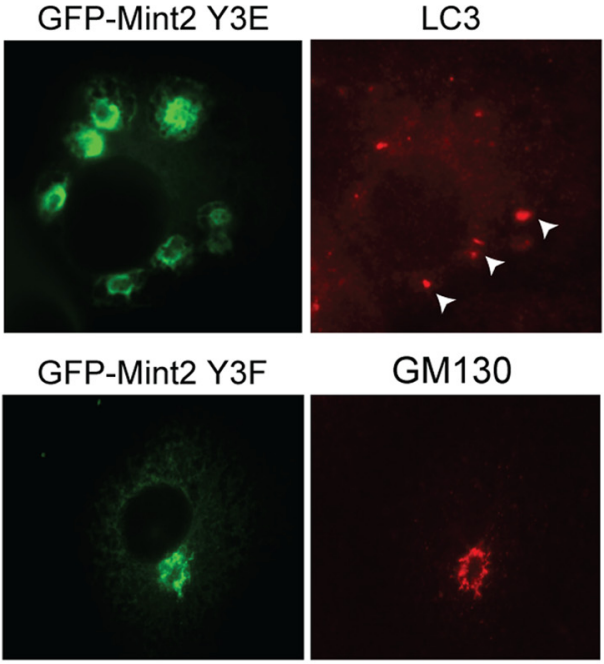

GM130
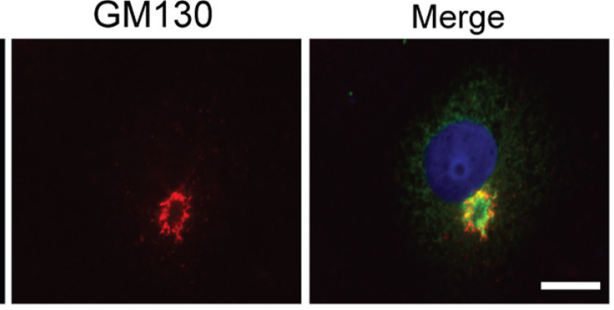

C

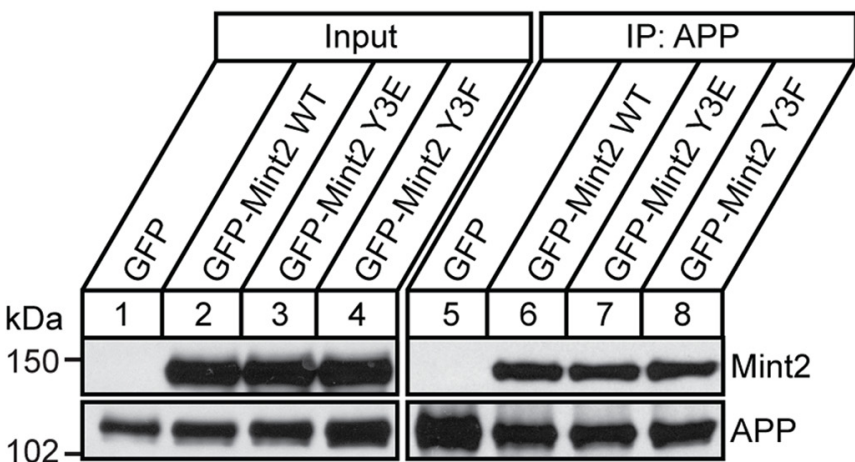

D

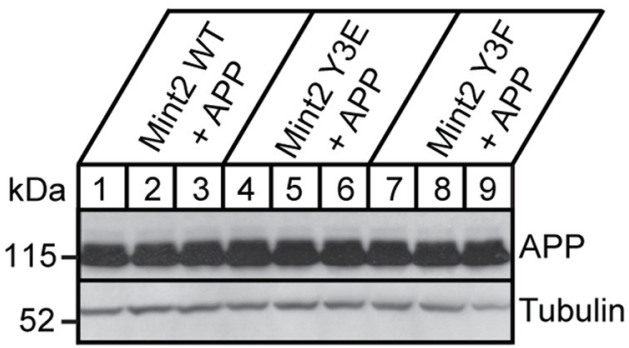

Figure 4. Mint2 phospho-mutants differentially affect APP localization without altering binding affinity to APP. A, COS7 cells were cotransfected with APP and GFP-Mint2-Y3E and stained with various intracellular markers. LC3-positive autophagosome marker colocalized with the GFP-Mint2-Y3E- and APP-containing vacuoles (marked by arrowheads) suggesting that phosphomimetic Mint2-Y3E mutant directs APP to the autophagic vesicles. B, GM-130-positive Golgi marker colocalized with GFP-Mint2-Y3F and APP indicating that phospho-resistant Mint2-Y3F mutant directs APP to the Golgi network pathway. Scale bars, $20 \mu \mathrm{m}$. $C$, HEK293T cells were cotransfected with APP and GFP-Mint2-WT, GFP-Mint2-Y3E, or GFP-Mint2-Y3F and subjected to immunoprecipitation with an APP antibody. Input (lanes 1-4) and precipitated fractions (lanes 5-8) were immunoblotted for Mint2 and APP demonstrating that Mint2 phospho-mutants did not alter the binding affinity to APP. D, Representative immunoblots of cell lysates from HEK293T cells cotransfected with APP and Mint2 phospho-mutants indicating that the phosphorylation state of Mint2 does not alter steady-state levels of APP.

internalized APP was colocalized with the autophagosome marker LC3 in neurons expressing the phosphomimetic Mint2Y3E mutant, suggesting that phosphorylation of Mint2 enhances APP sorting to autophagosomes (Fig. 6A). Quantitative analysis of confocal images revealed that $7 \pm 0.8 \%$ of internalized APP staining overlapped with LC3 in neurons expressing the phosphomimetic Mint2-Y3E mutant compared with Mint2-WT and phospho-resistant Mint2-Y3F mutant $(2.5 \pm 0.6 \%$ and $2.3 \pm$ $0.4 \%$, respectively). We also detected colocalization of endocytosed APP with the Golgi marker GM130 in neurons in all conditions, suggesting that a population of internalized APP is enriched in the retrograde endosome-to-Golgi sorting pathway
(Fig. 6B). Immunostaining was specific for internalized APP because no visible staining was observed in nonpermeabilized cells (data not shown).

\section{Mint2 phosphorylation regulates $\mathrm{A} \boldsymbol{\beta}$ generation in primary neurons} Because we found that the phosphomimetic Mint2-Y3E mutant favored sorting of endocytosed APP to the autophagic pathway in cultured $\mathrm{MTF}^{\mathrm{tg}}$ neurons and pathological autophagic vesicles have been shown to accumulate in APPswe/ $\mathrm{PS} 1 \Delta \mathrm{E} 9$ transgenic $\mathrm{AD}$ mice causing raised intracellular pools of $A \beta$ (Yu et al., 2005), we examined whether phosphorylation of Mint2 affects intracellular accumulation of $\mathrm{A} \beta$. We infected cultured MTF $^{\text {tg }}$ cortical neurons with cre-IRESMint2-WT, cre-IRES-Mint2-Y3E or creIRES-Mint2-Y3F and immunolabeled for A $\beta 42$ and APP (Fig. 7A). We found a significant $32 \%$ increase in intracellular A $\beta 42$ in MTF $^{\text {tg }}$ neurons infected with phosphomimeticMint2-Y3Emutantcompared with neurons expressing Mint2-WT and non-phosphorylatable Mint2-Y3F mutant, suggesting that phosphorylation of Mint2 promotes endocytic and autophagic pathways contributing to intracellular $\mathrm{A} \beta 42$ generation (Fig. 7B). In addition, we found no changes in the steady-state distribution of APP upon coexpression with Mint2 phosphomutants compared with Mint2-WT (Fig. 7C).

Because we found a significant increase in intracellular $A \beta 42$ in $\mathrm{MTF}^{\mathrm{tg}}$ neurons infected with phosphomimetic Mint2-Y3E mutant, we next examined whether phosphorylation of Mint2 affects A $\beta 42$ secretion into the extracellular medium. We measured secreted $A \beta$ levels by ELISA and found that conditioned medium from neurons expressing phosphomimetic Mint2-Y3E demonstrated a significant $15 \%$ reduction in $A \beta 42$ levels compared with neurons expressing Mint2WT (Fig. 7D). In contrast, we found a $24 \%$ increase in secreted $A \beta 42$ levels in neurons expressing the phospho-resistant Mint2-Y3F mutant suggesting that the phosphorylation state of Mint2 regulates A 342 secretion, possibly due to altered APP trafficking (Fig. $7 D$ ). We did not detect any changes in soluble APP or total APP expression levels in neurons infected with Mint2-WT, Mint2-Y3E or Mint2-Y3F phospho-mutants (Fig. 7E).

The increase in secreted $A \beta 42$ levels exhibited by neurons expressing the phospho-resistant Mint2-Y3F mutant could be guided by the intracellular sorting mechanisms that transport APP from the surface to the endosome, from the endosome back to the Golgi (Fig. 6) and recycling of APP from endosomes back to the cell surface for further APP processing and release of $A \beta$ into the extracellular medium. To examine whether internalized APP can potentially reinsert back into the plasma membrane 
via recycling endosomes for further APP processing, we measured APP recycling in cultured cortical $\mathrm{MTF}^{\text {tg }}$ neurons using a modified biotinylation assay. APP recycling was measured by the loss of internalized APP specifically labeled with cleavable disulfide-linked biotin. Neurons were surface biotinylated and transferred to $37^{\circ} \mathrm{C}$ for $5 \mathrm{~min}$ to allow endocytosis and the remaining surface biotin was cleaved with glutathione stripping buffer. Neurons were returned to $37^{\circ} \mathrm{C}$ for $30 \mathrm{~min}$ to allow any internalized APP to recycle back to the cell surface and surface-stripped a second time. The disappearance of biotinylated APP over time provides a measure of recycling rate. We found a significant $72 \%$ decrease in biotinylated APP with the phospho-resistant Mint2-Y3F mutant suggesting that non-phosphorylatable Mint2 enhances the recycling of APP by reinserting APP back into the plasma membrane (Fig. 7F,G). Together, these results showed that the phosphorylation state of Mint 2 regulates the distribution of internalized APP. When Mint2 is phosphorylated, internalized APP is sorted from endosomes to autophagosomes whereas when Mint2 is in a non-phosphorylatable state, internalized APP is directed from endosomes to the plasma membrane thus affecting $\mathrm{A} \beta$ secretion.

\section{Src kinase regulates $A \beta$ generation in primary neurons}

We next explored the effects of Src kinase on APP internalization, trafficking and processing by infecting $\mathrm{MTF}^{\text {tg }}$ neurons with a lentivirus encoding murine $\mathrm{c}$-Src kinase. Neurons were incubated at $37^{\circ} \mathrm{C}$ for 5 min to allow internalization of antibody-coupled APP and internalized APP was visualized following cell permeabilization using a fluorescentconjugated secondary antibody. Internalized APP was markedly different in control and c-Src overexpressing neurons (Fig. $8 A$ ). c-Src overexpressing neurons showed a significant $27 \%$ increase in internalized APP compared with control neurons, suggesting that Src kinase accelerates APP internalization (Fig. $8 B)$. Immunolabeling identifies a substantial rise in intracellular LC3-positive autophagic vesicles and A $\beta 42$ accumulation in neurons overexpressing c-Src compared with control neurons (Fig. 8C-E). However, there were no changes in total APP immunolabeling between control and c-Src expressing neurons (Fig. 8C,F). Overexpression of c-Src kinase significantly decreased secreted A $\beta 42$ levels by $44 \%$ compared with control neurons (Fig. 8G). We did not detect any changes in soluble APP or total APP expression levels in neurons infected with c-Src kinase (Fig. $8 H$ ). Together, these results suggest that activation of Src kinase and Src-mediated phosphorylation of Mint2 results in enhanced APP internalization, differential APP intracellular sorting favoring the autophagic pathway which is likely to account for changes in intracellular A $\beta 42$ accumulation and secretion.

\section{Discussion}

In the present study, we showed that Mint proteins are important in APP trafficking and A $\beta$ generation. We found that APP internalization was selectively inhibited in Mint knock-out neurons, indicating that Mint-mediated endocytosis of APP is an important step in regulating $A \beta$ production (Fig. 1). We demonstrated that the APP endocytic sorting processes are regulated by Src-mediated phosphorylation of Mint2. Mints are differentially phosphorylated by the Src family of kinases and we found that phosphorylation of Mint2 regulates APP trafficking (Figs. 2, 3). Phosphorylation of Mint2 accelerates APP endocytosis and sorts APP predominantly to LC3-positive autophagosomes which correlates with enhanced intracellular $\mathrm{A} \beta$ accumulation and reduced $\mathrm{A} \beta$ secretion. In contrast, a phospho-resistant Mint2 mutant sorts APP back to the plasma membrane to facilitate APP processing and enhanced $\mathrm{A} \beta$ secretion (Figs. 4-8). Thus, the phosphorylation state of Mint 2 guides APP to distinct sorting pathways to regulate APP trafficking and $\mathrm{A} \beta$ secretion: one pathway directed to LC3-positive autophagic vesicles after transitioning through the endosomal compartments which correlated with an increase in intracellular $\mathrm{A} \beta$ accumulation (Mint2 phosphorylation-dependent), while the other pathway directed to the plasma membrane for subsequent $\mathrm{APP}$ processing and $\mathrm{A} \beta$ secretion (Mint2 phosphorylation-inde- 
A
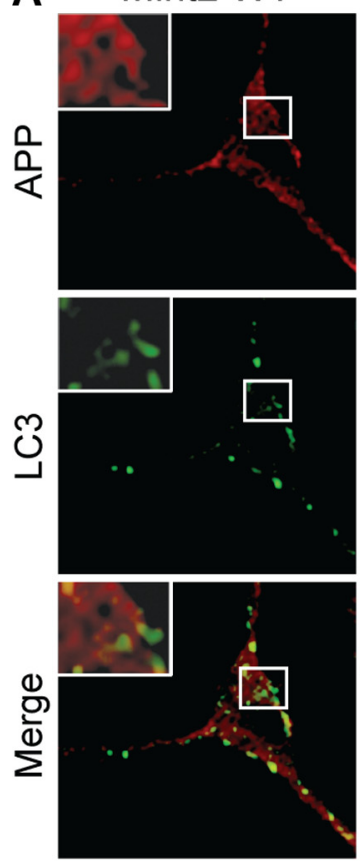

B
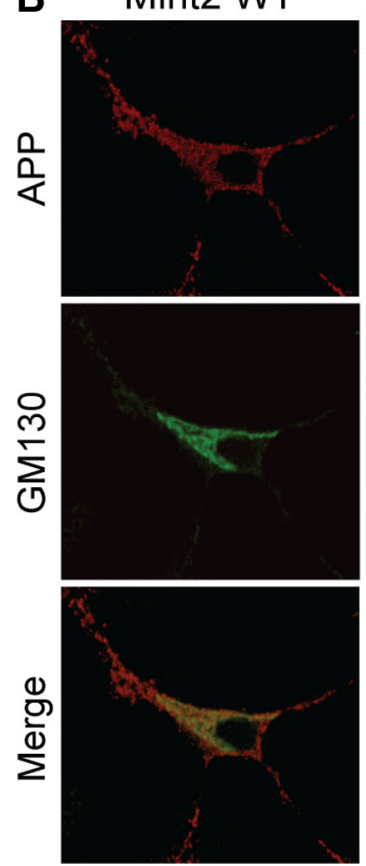

Mint2 Y3E
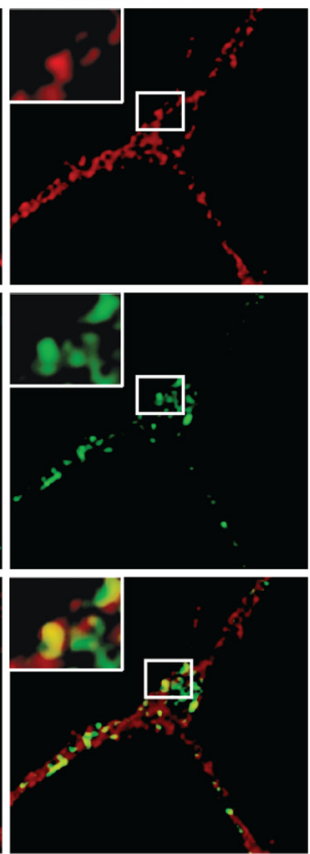

Mint2 Y3E
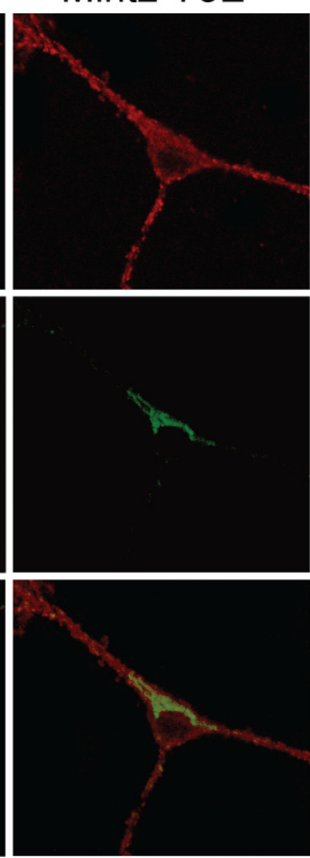

Mint2 Y3F
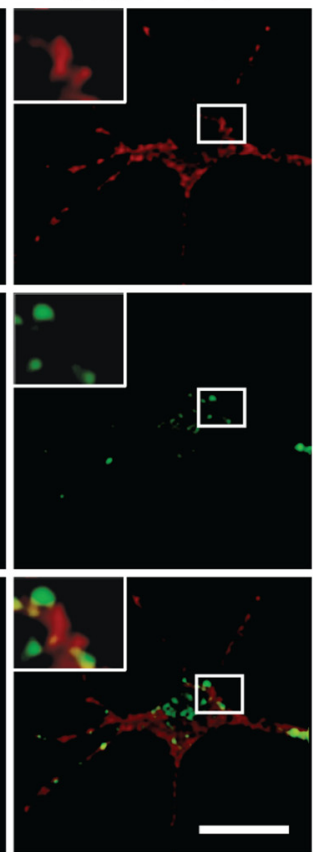

Mint2 Y3F
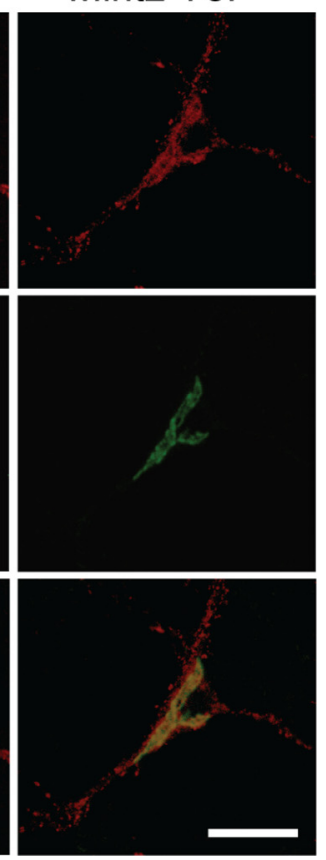

Figure 6. Phosphorylation of Mint2 modulates internalized APP localization. $A, B, M T F^{\text {tg }}$ hippocampal neurons were cultured and infected with lentiviral cre-IRES-Mint2-WT, cre-IRES-Mint2-Y3E, or cre-IRES-Mint2-Y3F. Live neurons were prelabeled with an extracellular APP antibody and after 5 min of internalization were fixed for immunostaining. Representative images of internalized APP (red) were visualized following cell permeabilization using fluorophore-conjugated antibody. $A$, Simultaneous staining for autophagosome LC3 (green) revealed extensive colocalization with internalized APP in phosphomimetic Mint2-Y3E mutant. Boxed inset represents a zoomed view $(n=2 / 15$ represents number of independent experiments and total number of neurons assessed in each experiment). $\boldsymbol{B}$, Double-labeling with anti-Golgi marker GM130 (green) indicated colocalization with internalized APP in all Mint2 conditions. Scale bars, $20 \mu \mathrm{m}$.

pendent; modeled in Fig. 8I). Our results indicate that Srcmediated phosphorylation of Mint2 regulates APP endocytic sorting pathways and suggest a mechanism for regulating intracellular and extracellular $\mathrm{A} \beta$ pools that may be relevant to $\mathrm{AD}$ pathogenesis.

In neurons, APP accumulates in the trans-Golgi complex after protein synthesis and undergoes a rapid turnover by $\alpha$-secretase at the plasma membrane (non-amyloidogenic pathway). Alternatively, APP is sorted to an endosomal pathway for processing by $\beta$-secretase initiating the amyloidogenic pathway. Therefore, APP endocytosis is a key step in $A \beta$ generation. The endosome has emerged as an important way-station organelle where the complex trafficking and processing of APP is orchestrated. The sorting signal that regulates endocytic processing of APP required for $A \beta$ generation is the highly conserved YENPTY sequence of the APP cytoplasmic tail (Haass et al., 1994). Knock-in mice that exclusively express APP with a C-terminal truncation that lacks the YENPTY endocytic motif have significantly reduced $\mathrm{A} \beta$ levels in the brain, suggesting that endocytosis is critical for $\mathrm{A} \beta$ generation (Ring et al., 2007). In addition, inhibition of clathrin-mediated endocytosis has been shown to lower interstitial $\mathrm{A} \beta$ levels in vivo (Cirrito et al., 2008). Several APPbinding proteins modulate the rate and amount of APP endocytosis and processing to $\mathrm{A} \beta$. Low density lipoprotein receptor-related protein 1 (LRP1) binds to APP and facilitates APP endocytosis resulting in increased $A \beta$ production whereas LRP1b, a homolog of LRP1, inhibits APP internalization and reduces $\mathrm{A} \beta$ production (Cam et al., 2004, 2005). Adaptor proteins that bind directly to the YENPTY endocytic motif of APP also modulate $A \beta$ secretion by regulating cell surface levels of APP. For example, overexpression of Fe65 and Dab1 increase $A \beta$ secretion, whereas Mint1 decreases A $\beta$ secretion (Borg et al., 1998; Sabo et al., 1999; Hoe et al., 2008). Moreover, it has been shown that apolipoprotein $\mathrm{E}$ receptor 2 triggers the endocytosis of APP and $\beta$-secretase leading to $\mathrm{A} \beta$ production that is mediated by Mints 1 and 2 in neuroblastoma cells (He et al., 2007). Given that these findings were based on heterologous expression systems, the physiological relevance of these APP-binding proteins in neurons is poorly understood. Indeed, we found that Mints play a significant role in APP cleavage and $A \beta$ production. That is, deletion of each of the three Mint proteins delays the age-dependent production of amyloid plaques in transgenic mouse models of $\mathrm{AD}$ (Ho et al., 2008). The phenotype of the Mint knock-outs asserts that Mints have an effect on APP trafficking. Here, we found that deletion of Mints significantly decreased APP endocytosis without affecting the steady-state surface expression of APP in primary neurons. These results suggest that 
membrane insertion of APP could be regulated by Mints where newly inserted APP could arise from stable intracellular pools through rapid translocation or by recycling of newly internalized APP back to the plasma membrane. Indeed, we found that Mints are involved in facilitation of APP insertion and the number of newly inserted APP was significantly decreased in Mint knock-out neurons (Fig. 1). Since there is strong evidence that presynaptic activity accelerates $\mathrm{A} \beta$ production by promoting APP endocytosis from the plasma membrane (Cirrito et al., 2005, 2008), and neuron-specific Mints 1 and 2 are important regulators of presynaptic neurotransmitter release (Ho et al., 2003, 2006), it is possible that Mints affect APP endocytosis in response to synaptic activity.

Endocytosed constituents can enter the autophagic pathway when late endosomes fuse with autophagosomes to generate an amphisome. This catabolic mechanism is essential for the degradation of aggregated proteins and organelles mediated through the lysosomal machinery (Gordon and Seglen, 1988). In neurons, there is substantial fusion of endosomes with autophagosomes (Larsen and Sulzer, 2002). Several studies have shown that the autophagic pathway is both induced and impaired in brains of humans with $\mathrm{AD}$ and $\mathrm{AD}$ mouse models leading to pathological accumulation of autophagic vacuoles containing $\mathrm{A} \beta$ that is detected by elevated levels of LC3, a marker for autophagosome formation (Nixon et al., 2005; Yu et al., 2005; Nixon, 2007; Boland et al., 2008). In APP/PS1 transgenic mice, autophagosomes were abundantly found in dystrophic neurites before extracellular $\mathrm{A} \beta$ deposition, suggesting that autophagic induction is an early response in disease development (Sanchez-Varo et al., 2012). In addition, autophagic compartments participate in $\mathrm{APP}$ processing and $\mathrm{A} \beta$ production and defects in the autophagic pathway can substantially lead to increases in intracellular $\mathrm{A} \beta$ pools which are more cytotoxic than extracellular $\mathrm{A} \beta$ ( $\mathrm{Yu}$ et al., 2004). Cognitive deficits reported in $\mathrm{AD}$ mouse models where intracellular $\mathrm{A} \beta$ levels are elevated in the absence of plaque deposition support the notion that intracellular $A \beta$ is more cytotoxic than extracellular A $\beta$ (Koistinaho et al., 2001; LaFerla et al., 2007; McGowan et al., 2005). Here, we showed that Src overexpression and/or Src phosphorylation of Mint2 increased the bulk of internalized APP to be destined for LC3-positive autophagosomes after transitioning through the endosomal compartments. The upregulation of LC3-positive autophagosome immunoreactivity corresponds to increased intracellular $\mathrm{A} \beta$ accumulation in neurons expressing either Src kinase or the phosphomimetic form of ${ }^{* * *} p<0.005$.
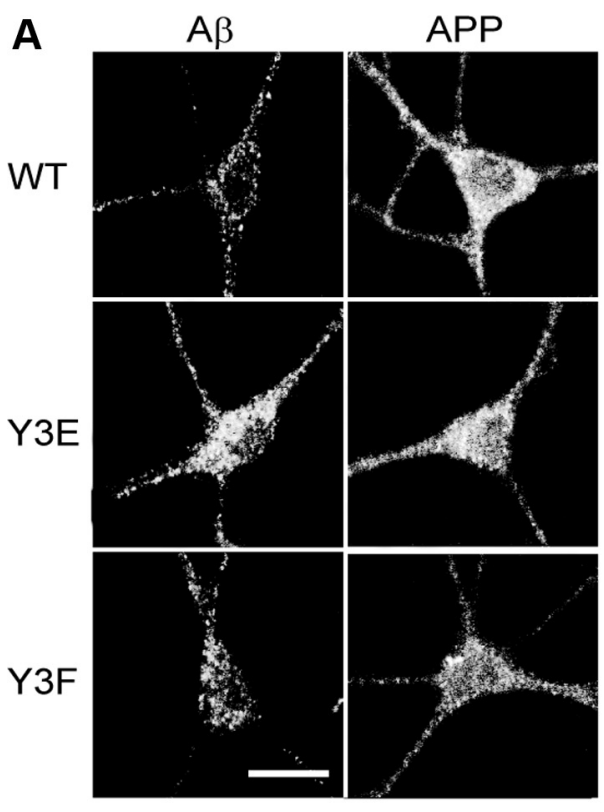

B
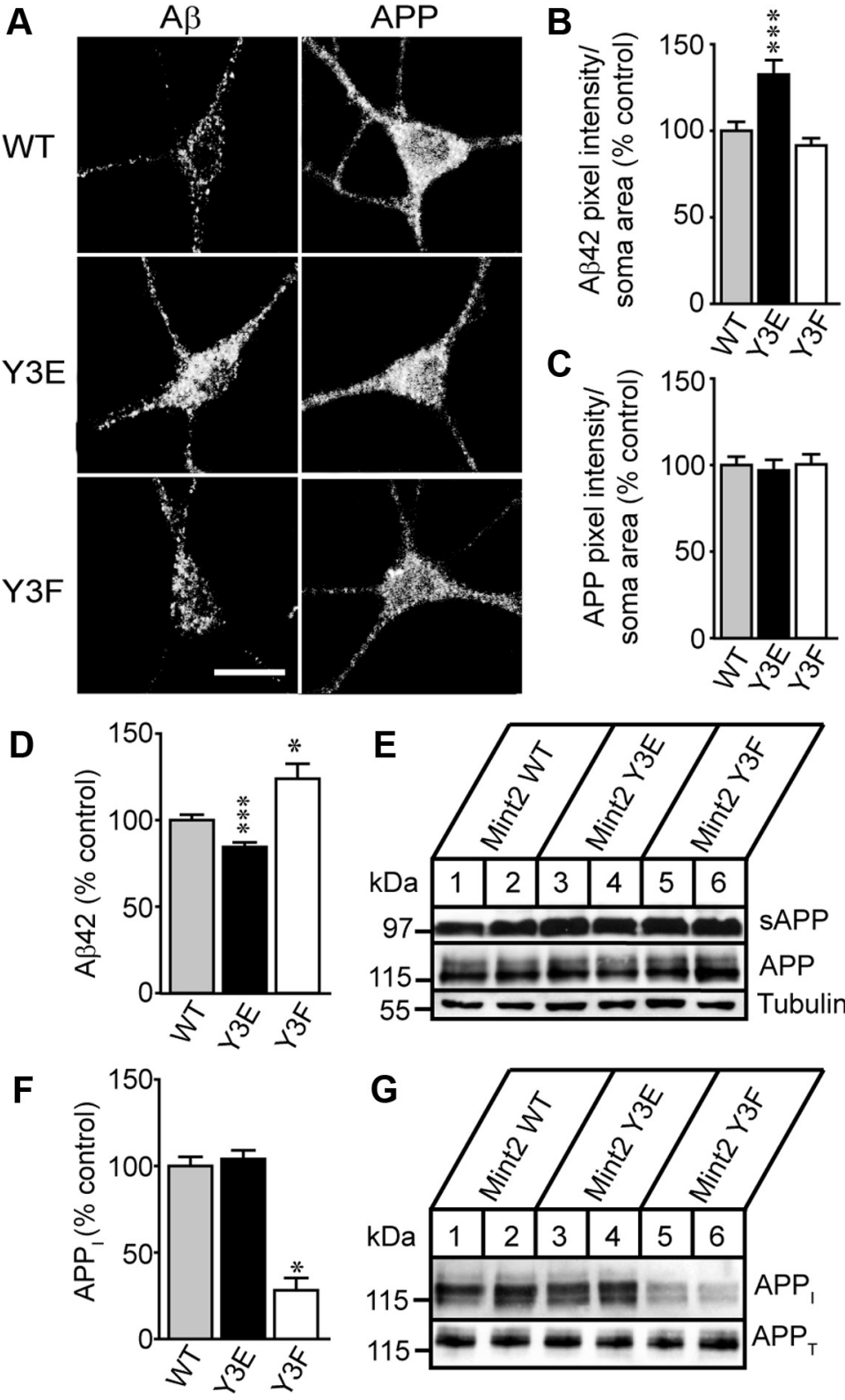

Figure 7. Phosphorylation of Mint2 increases intracellular $A \beta 42$ accumulation. $A$, MTF $^{\text {tg }}$ hippocampal neurons were cultured and infected with lentiviral cre-IRES-Mint2-WT, cre-IRES-Mint2-Y3E or cre-IRES-Mint2-Y3F and immunostained with A $\beta 42$ or APP antibody. Scale bar represents $10 \mu \mathrm{m} . \boldsymbol{B}, \boldsymbol{C}$, Quantitation of pixel intensity over soma area for A $\beta 42$ or APP and expressed as percentage control $(\boldsymbol{B}, n=3 / 32$ represents number of independent experiments and total number of neurons assessed; $\boldsymbol{C}, n=$ $2 / 17$ neurons). $\boldsymbol{D}$, Conditioned medium from phosphomimetic Mint2-Y3E mutant showed a significant reduction in $A \beta 42$ levels while phospho-resistant Mint2-Y3F mutant increased $A \beta 42$ levels by $24 \%$ compared with control neurons infected with Mint2-WT by ELISA. E, Representative immunoblots of soluble APP (SAPP), total APP, and Tubulin showed no significant changes in any of the proteins observed. $\boldsymbol{F}, \boldsymbol{G}$, Quantification and representative immunoblots for APP recycling assay. Surface biotinylated proteins were internalized for $5 \mathrm{~min}$ at $37^{\circ} \mathrm{C}$, recycled back to the cell surface for $30 \mathrm{~min}$ at $37^{\circ} \mathrm{C}$ and precipitated with Neutravidin agarose beads. Precipitated proteins were blotted for internalized APP (APP) and expressed as percentage control. ${ }^{*} p<0.05$,

Mint2. Conversely, the phospho-resistant form of Mint2 played an active role in recycling internalized APP back to the plasma membrane for further APP processing, which is consistent with the increased amount of $\mathrm{A} \beta$ released into the extracellular medium.

We also observed that a population of internalized APP is sorted to the Golgi apparatus. It is important to emphasize that our analysis of APP sorting was performed using the mutant APPswe, which results in enhanced efficiency of $\beta$-secretase 
A
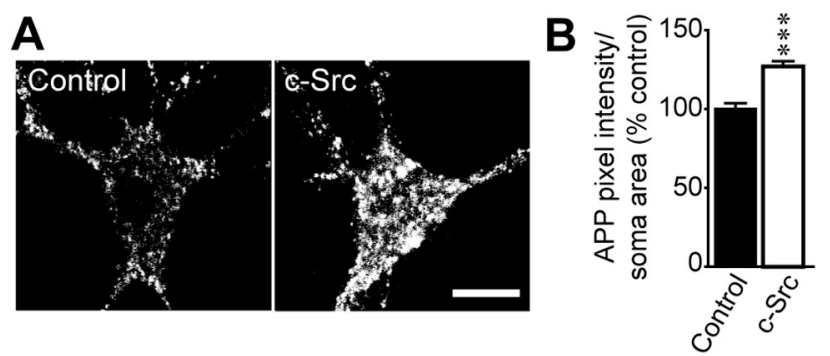

C

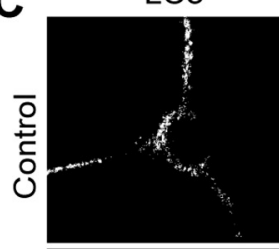

$A \beta 42$
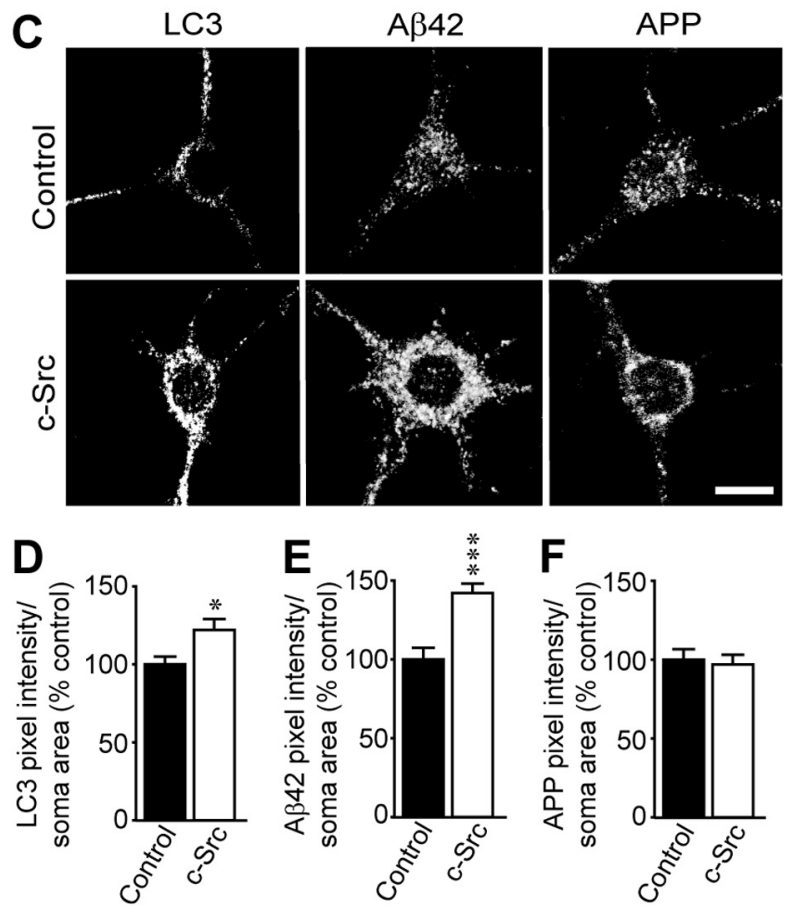

G

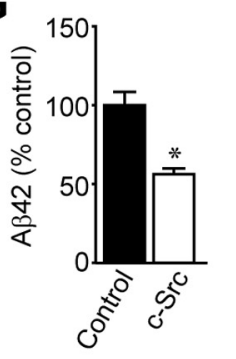

H
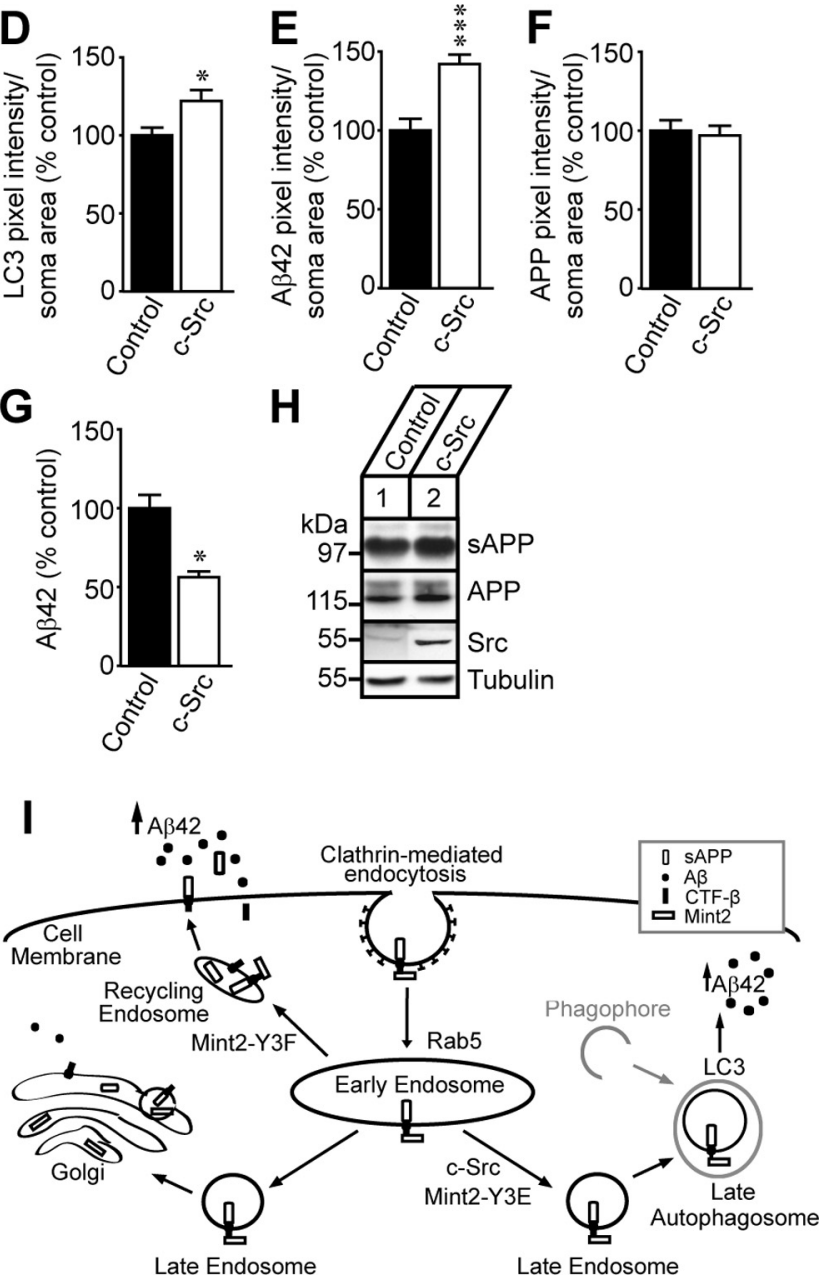

Figure 8. Src kinase effects on APP trafficking and processing. MTF ${ }^{\mathrm{tg}}$ neurons were cultured and infected with lentivirus encoding GFP (Control) or c-Src. A, Live cell endocytosis assay of MTF $^{\text {tg }}$ neurons incubated with an extracellular N-terminal APP antibody (22C11) and internalized for $5 \mathrm{~min}$ before stripping of excess surface antibody and fixation. Scale bar, $10 \mu \mathrm{m}$. $\boldsymbol{B}$, Internalized APP immunostaining was visualized by confocal microscopy and quantification of APP internalized was taken as a measure of pixel intensity within a defined soma area and cleavage of APP and robust generation of $A \beta$, as a model for AD (Haass et al., 1995; Perez et al., 1996, 1999; Sodhi et al., 2004). The APPswe sorting pathways differ from that of wild-type APP and accumulating evidence showed that both the binding of APP to $\beta$-secretase and the enhanced $\beta$-secretase activity for APP preferentially occurs within the trans-Golgi network for APPswe, while $\beta$-secretase cleavage for wild-type APP is commonly found in the endosome (Haass et al., 1995; Huse et al., 2000). $\beta$-secretase has been shown to traffic from the endosome to the trans-Golgi network via Golgi-localized, gamma adaptin earcontaining, ARF-binding (GGA) proteins (Bowman and Turkewitz, 2001; Bonifacino, 2004; He et al., 2005; Wahle et al., 2005). Specifically, coat protein GGA1 facilitates assembly of a complex containing $\beta$-secretase and the small GTPase ARF6 that is sufficient for initiating formation of an endocytic vesicle for retrograde transport to the trans-Golgi network (Wahle et al., 2005; Sannerud et al., 2011). Interestingly, Mints 2 and 3 can serve as ARF-dependent vesicle coat adaptor proteins that aid in APP trafficking back to the Golgi (Hill et al., 2003; Shrivastava-Ranjan et al., 2008) similar to the GGA1 protein responsible for retrograde transport of BACE1. Given that one function of an ARFbinding vesicular coat protein is to influence the trafficking itinerary of its cargo, we propose that Mint2 may serve as a signal to direct retrograde transport of APP vesicles to the trans-Golgi network. The cosorting of APP and $\beta$-secretase along this pathway may increase their interaction and facilitate $\mathrm{A} \beta$ production.

Our data does not exclude the possibility that Mints can be regulated by other tyrosine or serine/threonine kinases. Studying the primary sequence of the Mint proteins, we find that there are putative phosphorylation sites for kinases, such as protein kinase A, protein kinase $\mathrm{C}$ and calmodulin kinase II. It is possible that these other putative phosphorylation events have different consequences on Mints function from basic synaptic transmission to $\mathrm{AD}$ pathogenesis. The work that is highlighted here represents one such unique mechanism in which Src-mediated phosphorylation of Mint 2 regulates APP trafficking and $A \beta$ production. We showed that small changes in the phosphorylation state of Mint2 have striking consequences in endocytosed-APP sorting pathways leading either to increased intracellular $A \beta$ accumulation or enhanced $\mathrm{A} \beta$ secretion that is relevant to the development of $\mathrm{AD}$. Thus, increased Mints 1 and/or 2 expression in human AD brains (Jacobs et al., 2006), may be a risk factor for AD.

expressed as percentage control ( $n=2 / 40$ represents number of independent experiments and total number of neurons assessed). C, Neurons expressing GFP or C-Src were immunostained with $L C 3, A \beta 42$, or APP antibody. Scale bar, $10 \mu \mathrm{m}$. D-F, Quantifications of pixel intensity over soma area for $L C 3, A \beta 42$, and $A P P$ and expressed as percentage control $(\boldsymbol{D}, n=$ $2 / 21$ represents number of independent experiments and total number of neurons assessed; $\boldsymbol{E}$, $n=2 / 20 ; \boldsymbol{F}, n=2 / 14)$. $\boldsymbol{G}$, Secreted A $\beta 42$ levels were examined in neurons expressing GFP (control) or c-Src by ELISA. H, Representative immunoblots of soluble APP, total APP, Src, and Tubulin from neurons infected with control and c-Src $(n=9) .{ }^{*} p<0.05,{ }^{* * *} p<0.005 . I$, Model for the role of Mint2 phosphorylation in regulating the intracellular fate of internalized APP and A $\beta$ secretion events. Upon activation of clathrin-mediated endocytosis, cell-surface APP and Mint2 is internalized and destined for Rab5-positive early endosomes. APP-Mint2 internalization is accelerated in phosphomimetic Mint2-Y3E mutant. Constitutive phosphorylation of Mint2 sorts internalized APP for autophagosome vesicular trafficking leading to an accumulation of intracellular $A \beta 42$ immunoreactivity and decrease in secreted $A \beta 42$ levels. Alternatively, phospho-resistant Mint2-Y3F mutant showed a significant increase in secreted $A \beta 42$ levels that is due to APP recycling back to the cell surface which has been shown to favor amyloidogenic processing of APP. A population of internalized APP is sorted to the Golgi apparatus. 


\section{References}

Biederer T, Cao X, Südhof TC, Liu X (2002) Regulation of APP-dependent transcription complexes by Mint/X11s: differential functions of Mint isoforms. J Neurosci 22:7340-7351.

Blom N, Gammeltoft S, Brunak S (1999) Sequence and structure-based prediction of eukaryotic protein phosphorylation sites. J Mol Biol 294:1351-1362.

Boland B, Kumar A, Lee S, Platt FM, Wegiel J, Yu WH, Nixon RA (2008) Autophagy induction and autophagosome clearance in neurons: relationship to autophagic pathology in Alzheimer's disease. J Neurosci 28:6926-6937.

Bolte S, Cordelières FP (2006) A guided tour into subcellular colocalization analysis in light microscopy. J Microscopy 224:213-232.

Bonifacino JS (2004) The GGA proteins: adaptors on the move. Nat Rev Mol Cell Biol 5:23-32.

Bonifacino JS, Traub LM (2003) Signals for sorting of transmembrane proteins to endosomes and lysosomes. Annu Rev Biochem 72:395-447.

Borg JP, Ooi J, Levy E, Margolis B (1996) The phosphotyrosine interaction domains of X11 and FE65 bind to distinct sites on the YENPTY motif of amyloid precursor protein. Mol Cell Biol 16:6229-6241.

Borg JP, Yang Y, De Taddéo-Borg M, Margolis B, Turner RS (1998) The X11alpha protein slows cellular amyloid precursor protein processing and reduces Abeta40 and Abeta42 secretion. J Biol Chem 273:14761-14766.

Bowman GR, Turkewitz AP (2001) Analysis of a mutant exhibiting conditional sorting to dense core secretory granules in Tetrahymena thermophila. Genetics 159:1605-1616.

Cam JA, Zerbinatti CV, Knisely JM, Hecimovic S, Li Y, Bu G (2004) The low density lipoprotein receptor-related protein $1 \mathrm{~B}$ retains beta-amyloid precursor protein at the cell surface and reduces amyloid-beta peptide production. J Biol Chem 279:29639-29646.

Cam JA, Zerbinatti CV, Li Y, Bu G (2005) Rapid endocytosis of the low density lipoprotein receptor-related protein modulates cell surface distribution and processing of the beta-amyloid precursor protein. J Biol Chem 280:15464-15470.

Cirrito JR, Yamada KA, Finn MB, Sloviter RS, Bales KR, May PC, Schoepp DD, Paul SM, Mennerick S, Holtzman DM (2005) Synaptic activity regulates interstitial fluid amyloid-beta levels in vivo. Neuron 48:913-922.

Cirrito JR, Kang JE, Lee J, Stewart FR, Verges DK, Silverio LM, Bu G, Mennerick S, Holtzman DM (2008) Endocytosis is required for synaptic activity-dependent release of amyloid-beta in vivo. Neuron 58:42-51.

Delom F, Fessart D (2011) Role of phosphorylation in the control of clathrin-mediated internalization of GPCR. Int J Cell Biol 2011:246954.

Gianni D, Zambrano N, Bimonte M, Minopoli G, Mercken L, Talamo F, Scaloni A, Russo T (2003) Platelet-derived growth factor induces the beta-gamma-secretase-mediated cleavage of Alzheimer's amyloid precursor protein through a Src-Rac-dependent pathway. J Biol Chem 278:9290-9297.

Gordon PB, Seglen PO (1988) Prelysosomal convergence of autophagic and endocytic pathways. Biochem Biophys Res Commun 151:40 - 47.

Haass C, Koo EH, Teplow DB, Selkoe DJ (1994) Polarized secretion of betaamyloid precursor protein and amyloid beta-peptide in MDCK cells. Proc Natl Acad Sci U S A 91:1564-1568.

Haass C, Lemere CA, Capell A, Citron M, Seubert P, Schenk D, Lannfelt L, Selkoe DJ (1995) The Swedish mutation causes early-onset Alzheimer's disease by beta-secretase cleavage within the secretory pathway. Nat Med 1:1291-1296.

Hardy J, Selkoe DJ (2002) The amyloid hypothesis of Alzheimer's disease: progress and problems on the road to therapeutics. Science 297:353-356.

He X, Li F, Chang WP, Tang J (2005) GGA proteins mediate the recycling pathway of memapsin 2 (BACE). J Biol Chem 280:11696-11703.

He X, Cooley K, Chung CH, Dashti N, Tang J (2007) Apolipoprotein receptor 2 and X11 alpha/beta mediate apolipoprotein E-induced endocytosis of amyloid-beta precursor protein and beta-secretase, leading to amyloidbeta production. J Neurosci 27:4052-4060.

Hill K, Li Y, Bennett M, McKay M, Zhu X, Shern J, Torre E, Lah JJ, Levey AI, Kahn RA (2003) Munc18 interacting proteins: ADP-ribosylation factor-dependent coat proteins that regulate the traffic of betaAlzheimer's precursor protein. J Biol Chem 278:36032-36040.

Ho A, Morishita W, Hammer RE, Malenka RC, Sudhof TC (2003) A role for Mints in transmitter release: Mintl knockout mice exhibit impaired
GABAergic synaptic transmission. Proc Natl Acad Sci U S A 100:1409-1414

Ho A, Morishita W, Atasoy D, Liu X, Tabuchi K, Hammer RE, Malenka RC, Südhof TC (2006) Genetic analysis of Mint/X11 proteins: essential presynaptic functions of a neuronal adaptor protein family. J Neurosci 26:13089-13101.

Ho A, Liu X, Südhof TC (2008) Deletion of Mint proteins decreases amyloid production in transgenic mouse models of Alzheimer's disease. J Neurosci 28:14392-14400.

Hoe HS, Minami SS, Makarova A, Lee J, Hyman BT, Matsuoka Y, Rebeck GW (2008) Fyn modulation of Dab1 effects on amyloid precursor protein and ApoE receptor 2 processing. J Biol Chem 283:6288-6299.

Howell BW, Gertler FB, Cooper JA (1997) Mouse disabled (mDab1): a Src binding protein implicated in neuronal development. EMBO J 16:121-132.

Huse JT, Pijak DS, Leslie GJ, Lee VM, Doms RW (2000) Maturation and endosomal targeting of beta-site amyloid precursor protein-cleaving enzyme. The Alzheimer's disease beta-secretase. J Biol Chem 275: 33729-33737.

Jacobs EH, Williams RJ, Francis PT (2006) Cyclin-dependent kinase 5, Munc18a and Munc18-interacting protein 1/X11alpha protein upregulation in Alzheimer's disease. Neuroscience 138:511-522.

Kametaka S, Mattera R, Bonifacino JS (2005) Epidermal growth factordependent phosphorylation of the GGA3 adaptor protein regulates its recruitment to membranes. Mol Cell Biol 25:7988-8000.

Koistinaho M, Ort M, Cimadevilla JM, Vondrous R, Cordell B, Koistinaho J, Bures J, Higgins LS (2001) Specific spatial learning deficits become severe with age in beta-amyloid precursor protein transgenic mice that harbor diffuse beta-amyloid deposits but do not form plaques. Proc Natl Acad Sci U S A 98:14675-14680.

Koo EH, Squazzo SL (1994) Evidence that production and release of amyloid beta-protein involves the endocytic pathway. J Biol Chem 269:17386-17389.

LaFerla FM, Green KN, Oddo S (2007) Intracellular amyloid-beta in Alzheimer's disease. Nat Rev Neurosci 8:499-509.

Larsen KE, Sulzer D (2002) Autophagy in neurons: a review. Histol Histopathol 17:897-908.

Lau KF, McLoughlin DM, Standen C, Miller CC (2000) X11 alpha and X11 beta interact with presenilin-1 via their PDZ domains. Mol Cell Neurosci 16:557-565.

Lee G (2005) Tau and Src family tyrosine kinases. Biochim Biophys Acta 1739:323-330.

Lu W, Man H, Ju W, Trimble WS, MacDonald JF, Wang YT (2001) Activation of synaptic NMDA receptors induces membrane insertion of new AMPA receptors and LTP in cultured hippocampal neurons. Neuron 29:243-254.

Manders EM, Stap J, Brakenhoff GJ, van Driel R, Aten JA (1992) Dynamics of three-dimensional replication patterns during the S-phase, analysed by double labelling of DNA and confocal microscopy. J Cell Sci 103:857-862.

Matos MF, Xu Y, Dulubova I, Otwinowski Z, Richardson JM, Tomchick DR, Rizo J, Ho A (2012) Autoinhibition of Mintl adaptor protein regulates APP binding and processing. Proc Natl Acad Sci U S A 109:3802-3807.

McGowan E, Pickford F, Kim J, Onstead L, Eriksen J, Yu C, Skipper L, Murphy MP, Beard J, Das P, Jansen K, Delucia M, Lin WL, Dolios G, Wang R, Eckman CB, Dickson DW, Hutton M, Hardy J, Golde T (2005) Abeta42 is essential for parenchymal and vascular amyloid deposition in mice. Neuron 47:191-199.

Nixon RA (2007) Autophagy, amyloidogenesis and Alzheimer's disease. J Cell Sci 120:4081-4091.

Nixon RA, Wegiel J, Kumar A, Yu WH, Peterhoff C, Cataldo A, Cuervo AM (2005) Extensive involvement of autophagy in Alzheimer's disease: an immuno-electron microscopy study. J Neuropathol Exp Neurol 64:113-122.

Obenauer JC, Cantley LC, Yaffe MB (2003) Scansite 2.0: proteome-wide prediction of cell signaling interactions using short sequence motifs. Nucleic Acids Res 31:3635-3641.

Okamoto M, SüdhofTC (1997) Mints, Munc18-interacting proteins in synaptic vesicle exocytosis. J Biol Chem 272:31459-31464.

Okamoto M, SüdhofTC (1998) Mint 3: a ubiquitous mint isoform that does not bind to munc18-1 or -2. Eur J Cell Biol 77:161-165.

Perez RG, Squazzo SL, Koo EH (1996) Enhanced release of amyloid beta- 
protein from codon 670/671 "Swedish" mutant beta-amyloid precursor protein occurs in both secretory and endocytic pathways. J Biol Chem 271:9100-9107.

Perez RG, Soriano S, Hayes JD, Ostaszewski B, Xia W, Selkoe DJ, Chen X, Stokin GB, Koo EH (1999) Mutagenesis identifies new signals for betaamyloid precursor protein endocytosis, turnover, and the generation of secreted fragments, including Abeta42. J Biol Chem 274:18851-18856.

Ring S, Weyer SW, Kilian SB, Waldron E, Pietrzik CU, Filippov MA, Herms J, Buchholz C, Eckman CB, Korte M, Wolfer DP, Müller UC (2007) The secreted beta-amyloid precursor protein ectodomain APPs alpha is sufficient to rescue the anatomical, behavioral, and electrophysiological abnormalities of APP-deficient mice. J Neurosci 27:7817-7826.

Sabo SL, Lanier LM, Ikin AF, Khorkova O, Sahasrabudhe S, Greengard P, Buxbaum JD (1999) Regulation of beta-amyloid secretion by FE65, an amyloid protein precursor-binding protein. J Biol Chem 274:7952-7957.

Sanchez-Varo R, Trujillo-Estrada L, Sanchez-Mejias E, Torres M, BagliettoVargas D, Moreno-Gonzalez I, De Castro V, Jimenez S, Ruano D, Vizuete M, Davila JC, Garcia-Verdugo JM, Jimenez AJ, Vitorica J, Gutierrez A (2012) Abnormal accumulation of autophagic vesicles correlates with axonal and synaptic pathology in young Alzheimer's mice hippocampus. Acta Neuropathol 123:53-70.

Sannerud R, Declerck I, Peric A, Raemaekers T, Menendez G, Zhou L, Veerle B, Coen K, Munck S, De Strooper B, Schiavo G, Annaert W (2011) ADP ribosylation factor 6 (ARF6) controls amyloid precursor protein (APP) processing by mediating the endosomal sorting of BACE1. Proc Natl Acad Sci U S A 108:E559-E568.

Shrivastava-Ranjan P, Faundez V, Fang G, Rees H, Lah JJ, Levey AI, Kahn RA (2008) Mint3/X11gamma is an ADP-ribosylation factor-dependent adaptor that regulates the traffic of the Alzheimer's precursor protein from the trans-Golgi network. Mol Biol Cell 19:51-64.
Small SA, Gandy S (2006) Sorting through the cell biology of Alzheimer's disease: intracellular pathways to pathogenesis. Neuron 52:15-31.

Sodhi CP, Rampalli S, Perez RG, Koo EH, Quinn B, Gottardi-Littell NR (2004) The endocytic pathway is required for increased Abeta 42 secretion during apoptosis. Brain Res Mol Brain Res 128:201-211.

Thinakaran G, Koo EH (2008) Amyloid precursor protein trafficking, processing, and function. J Biol Chem 283:29615-29619.

Wahle T, Prager K, Raffler N, Haass C, Famulok M, Walter J (2005) GGA proteins regulate retrograde transport of BACE1 from endosomes to the trans-Golgi network. Mol Cell Neurosci 29:453-461.

Wilde A, Beattie EC, Lem L, Riethof DA, Liu SH, Mobley WC, Soriano P, Brodsky FM (1999) EGF receptor signaling stimulates SRC kinase phosphorylation of clathrin, influencing clathrin redistribution and EGF uptake. Cell 96:677-687.

Williamson R, Scales T, Clark BR, Gibb G, Reynolds CH, Kellie S, Bird IN, Varndell IM, Sheppard PW, Everall I, Anderton BH (2002) Rapid tyrosine phosphorylation of neuronal proteins including tau and focal adhesion kinase in response to amyloid-beta peptide exposure: involvement of Src family protein kinases. J Neurosci 22:10-20.

Yu WH, Kumar A, Peterhoff C, Shapiro Kulnane L, Uchiyama Y, Lamb BT, Cuervo AM, Nixon RA (2004) Autophagic vacuoles are enriched in amyloid precursor protein-secretase activities: implications for beta-amyloid peptide overproduction and localization in Alzheimer's disease. Int J Biochem Cell Biol 36:2531-2540.

Yu WH, Cuervo AM, Kumar A, Peterhoff CM, Schmidt SD, Lee JH, Mohan PS, Mercken M, Farmery MR, Tjernberg LO, Jiang Y, Duff K, Uchiyama Y, Näslund J, Mathews PM, Cataldo AM, Nixon RA (2005) Macroautophagy—a novel Beta-amyloid peptide-generating pathway activated in Alzheimer's disease. J Cell Biol 171:87-98. 